\title{
Colonic Transit Disorder Mediated by Downregulation of Interstitial Cells of Cajal/ Anoctamin-1 in Dextran Sodium Sulfate-induced Colitis Mice
}

\author{
Chen Lu, ${ }^{1,2}$ Hongli Lu, ${ }^{1}$ Xu Huang, ${ }^{1}$ Shaohua Liu, ${ }^{3}$ Jingyu Zang, ${ }^{2}$ Yujia Li, ${ }^{1}$ Jie Chen, ${ }^{2}$ and Wenxie Xu ${ }^{1 *}$ \\ ${ }^{1}$ Department of Anatomy and Physiology, Shanghai Jiao Tong University School of Medicine, Shanghai, China; ${ }^{2}$ Department of Pediatric \\ Surgery, Xin Hua Hospital, Affiliated to Shanghai Jiao Tong University School of Medicine, Shanghai, China; and ${ }^{3}$ Department of \\ Anesthesiology, South Renji Hospital, Affiliated to Shanghai Jiao Tong University School of Medicine, Shanghai, China
}

\section{Background/Aims}

Interstitial cells of Cajal (ICC) and their special calcium-activated chloride channel, anoctamin-1 (ANO1) play pivotal roles in regulating colonic transit. This study is designed to investigate the role of ICC and the ANO1 channel in colonic transit disorder in dextran sodium sulfate (DSS)-treated colitis mice.

\section{Methods}

Colonic transit experiment, colonic migrating motor complexes (CMMCs), smooth muscle spontaneous contractile experiments, intracellular electrical recordings, western blotting analysis, and quantitative polymerase chain reaction were applied in this study.

\section{Results}

The mRNA and protein expressions of c-KIT and ANO1 channels were significantly decreased in the colons of DSS-colitis mice. The colonic artificial fecal-pellet transit experiment in vitro was significantly delayed in DSS-colitis mice. The CMMCs and smooth muscle spontaneous contractions were significantly decreased by 5-nitro-2-(3-phenylpropylamino)benzoic acid (NPPB), an ANO1 channel blocker, and NG-Nitro-L-arginine methyl ester hydrochloride (L-NAME), an inhibitor of nitric oxide synthase activity, in DSS-colitis mice compared with that of control mice. Intracellular electrical recordings showed that the amplitude of NPPB-induced hyperpolarization was more positive in DSS-colitis mice. The electric field stimulation-elicited nitric-dependent slow inhibitory junctional potentials were also more positive in DSS-colitis mice than those of control mice.

\section{Conclusion}

The results suggest that colonic transit disorder is mediated via downregulation of the nitric oxide/ICC/ANO1 signalling pathway in DSS-colitis mice.

(J Neurogastroenterol Motil 2019;25:316-331)

\section{Key Words}

Anoctamin-1; Colitis; Interstitial cells of Cajal; Nitric oxide synthase; Down-regulation

Received: October 30, 2018 Revised: January 15, 2019 Accepted: February 26, 2019

(.) This is an Open Access article distributed under the terms of the Creative Commons Attribution Non-Commercial License (http://creativecommons. org/licenses/by-nc/4.0) which permits unrestricted non-commercial use, distribution, and reproduction in any medium, provided the original work is properly cited.

*Correspondence: Wenxie $\mathrm{Xu}, \mathrm{PhD}$ Department of Anatomy and Physiology, Shanghai Jiao Tong University School of Medicine, No. 800, Dongchuan Road, Shanghai 200240, China Tel: +86-21-34205639, Fax: +86-21-34205639, E-mail: wenxiexu@sjtu.edu.cn 


\section{Introduction}

Among the various diseases of the lower digestive system, the incidence of inflammatory bowel disease (IBD), which consists of Crohn's disease and ulcerative colitis (UC), is increasing yearly, and appears as severe structural and functional disorders. ${ }^{1,2}$ However, in all functional alterations, colonic dysmotility is an important clinical symptom. ${ }^{3}$ Colonic migrating motor complexes (CMMC) is known as the main form of colonic transit, and it has been demonstrated that its generation is regulated by the SIP syncytium comprising of smooth muscle cells (SMCs), interstitial cells of Cajal (ICC), and platelet-derived growth factor receptor $\alpha$-positive $\left(\mathrm{PDGFR} \alpha^{+}\right.$) cells that are electrically coupled from smooth muscle tissue. ${ }^{4-6}$ Thus, the tone of the colonic smooth muscle is a pivotal factor for generating motor activity and permitting changes in volume to accommodate stool in the colon.

In recent years, $\mathrm{UC}$ has been prevalent among gastrointestinal (GI) diseases, and it is accompanied by abnormal colonic motility and transit dysfunction. ${ }^{7}$ These motor obstructions were believed to occur due to changing colonic neuromuscular components, including enteric neurons and the SIP syncytium, and the integration of structure and function are critical requirements to mediate the coordination of neuromodulatory motor patterns in the colon. ${ }^{8,9} \mathrm{ICC}$, as an important source of colon motility, have been identified in several GI transit dysmotility diseases. ${ }^{5}$ Bernardini et $\mathrm{al}^{8}$ have found quantitative variations of myenteric neuro-glial cells and ICC through immunohistochemical analysis, which illustrates considerable alterations of the colonic motor abnormalities in UC patients. Although considerable progress has been achieved in studying the pathogenesis and treatment of IBD, little is known regarding the alterations of colonic dysmotility in UC. Therefore, this study centered on the role of the ICC/anoctamin-1 (ANO1) signal channel in leading to colonic transit disorder in UC.

ICCs have become well known since their ultrastructural evidence was first suggested and they were described as a pacemaker of the GI tract through driving or conducting the excitatory transmission between neurons and smooth muscles in enteric neuraltransit. ${ }^{5,9,10}$ To date, most s on ICC have recognized that they share common anatomical spaces with SMCs coupled electrically, and that they involve critical regulatory role in neuro-gastroenterology. In addition, more recently, the new findings revealed that ANO1, which is a calcium-activated chloride channel, is highly and exclusively expressed by ICC throughout the GI tract. ${ }^{11,12}$ Moreover, ANO1 supports an important and fundamental role in the pace- maker activity of generating slow waves. ${ }^{12,13}$

In addition, recent studies have shown that only a small amount of the neurotransmitter released by the varicose body of nerve terminal directly spreads to the smooth muscle to play a regulatory role, but the majority of neurotransmitters for the regulation of smooth muscle are not directly conducted by neurotransmitters, such as nitric oxide (NO), released from the enteric nervous system, but through the SIP syncytium consisting of SMC, intramuscular ICC (ICC-IM), and PDGFR $\alpha^{+}$cells. ${ }^{6,9}$ ICC have been accepted by most researchers to integrate neuronal signals to the SMC syncytium in order to guarantee functional GI motility. ${ }^{14}$ The function of $\mathrm{NO}$ in mediating effects for ICC indicate that basal enteric NO release probably acts via myenteric ICC to influence the generation of spontaneous contractions. ${ }^{15} \mathrm{NO}$ inhibited ANO1 channel on ICCIM, and then inhibited the voltage-dependent calcium channels on SMCs through the gap junction, leading to cell hyperpolarization, which eventually induced the relaxation of smooth muscle. ${ }^{16}$ Therefore, the inhibitory effect of $\mathrm{NO}$ can be considered to be mainly through ICC-IM, which can influence the generation of spontaneous contractions and the initiation of slow inhibitory junctional potentials (sIJPs) through ICC. ${ }^{17,18}$ ICC, as post-junctional cells, conducts the inhibitory neurotransmitter $\mathrm{NO}$, which transforms as nitric signal. ${ }^{17,19}$ However, the mechanism of colon transit disorder mainly from the signaling pathway of NO-ICC-ANO1-SMC in dextran sodium sulfate (DSS)-induced colitis mice has not been studied previously.

At present, we used a DSS-colitis mouse model to study the role of ICC in colonic dysmotility and dysfunction. Individual protein and gene expressions of ICC and ANO1 channels were compared between control and DSS-colitis mice using molecular biological methods. Moreover, the functional changes of $\mathrm{NO}$ and ANO1 channels in ICC were explored through observing the reactions to ANO1 and $\mathrm{NO}$ blockers. The results clarify that the role of the $\mathrm{NO} / \mathrm{ICC} / \mathrm{ANO} 1$ signalling pathway is downregulated in DSScolitis mice, thus, resulting in the colonic transit dysmotility that are observed in IBD patients.

\section{Materials and Methods}

\section{Ethical Consideration}

This study was operated fully in compliance with the rules of the Guide for the Care and Use of Laboratory Animals of the Science and Technology Commission of PRC (STCC Publication No. 2 , revised 1988). The protocol was supported by the Committee on 
the Ethics of Animal Experiments of Shanghai Jiao Tong University School of Medicine (Permit No. Hu 686-2009).

\section{Animals and the Dextran Sodium Sulfate-treated Colitis Mouse Model}

Adult male ICR mice (5 weeks old and weighing approximately $30 \mathrm{~g}$ ) were obtained from the Experimental Animal Center of the Chinese Academy of Sciences (Shanghai, China) in this study. Twenty mice were randomly divided into 2 groups: a control group and a DSS-induced group. The DSS group was treated through drinking 3\% DSS (molecular weight 36 000-50 000 kDa; SigmaAldrich, St. Louis, MO, USA) water for 7 days, and examination for clinical signs of colitis (ie, weight loss, stool consistency, and fecal blood) were recorded daily. All mice were housed at $20-25^{\circ} \mathrm{C}$ temperature under a 12-hour light/dark cycle with free access to water and food. The colons were removed from the abdomen after 7 days and then colon length were measured and recorded.

\section{Hematoxylin and Eosin Staining}

This procedure involves tissue fixation, paraffin embedding, and histological scoring. The colons were dissected, opened longitudinally, and washed with phosphate buffered saline followed by fixation with $10 \%$ buffered formalin. The tissue was embedded in paraffin, cut into $5 \mu \mathrm{m}$ sections, and stained with H\&E. Histological assessment of colitis was performed to use a standardized semiquantitative scoring system and referred to a pathologist (Paul Jedlicka) who was blinded to the time point, strain, and treatment groups. Briefly, scores were given for 3 histologic parameters: (1) active inflammation (granulocyte infiltration), (2) chronic inflammation (lymphocytes, plasma cells, and macrophages in the mucosa and submucosa), and (3) villus distortion (flattening and/or widening of normal villous architecture). ${ }^{20,21}$

\section{Western Blot Analysis}

Protein samples were extracted from colon smooth muscle tissues. The samples were lysed in radioimmunoprecipitation assay buffer (1:100; Beyotime Chemical Co, Jiangsu, China) and phenylmethanesulphonylfluoride buffer (Beyotime Chemical Co) that contained a protease inhibitor cocktail (Beyotime Chemical Co). The suspension was centrifuged at 12000 rotations for 15 minutes at $4^{\circ} \mathrm{C}$. The protein samples ( $40 \mu \mathrm{g} /$ lane) were separated via $10 \%$ or $8 \%$ sodium dodecyl sulphate polyacrylamide gel electrophoresis (SDS-PAGE) and transferred from the polyacrylamide gel to a polyvinylidenedifluoride membrane using a Semi-Dry Transblot unit (Bio-Rad Laboratories, Inc, Hercules, CA, USA). After blocking with $5 \%$ non-fat milk in $0.1 \%$ Tris-buffered saline/Tween 20 , then incubating the primary antibodies in polyvinylidenedifluoride membranes overnight at $4^{\circ} \mathrm{C}$ and for 120 minutes with secondary antibodies at $24^{\circ} \mathrm{C}$. The antibodies used were as follows: c-KIT monoclonal antibodies (1:1000; Cell Signaling Technology, Boston, MA, USA), anti-TMEM16A (ANO1) antibody (1:500; Abcam, Cambridge, MA, USA), anti-tubulin (1:1000; Beyotime Chemical Co), anti-rabbit IgG, HRP-linked antibody (1:1000; Cell Signaling), and anti-mouse IgG, HRP-linked antibody (1:1000; Cell Signaling Technology).

\section{RNA Isolation and Reverse-transcription Quantitative Polymerase Chain Reaction}

All RNA from colonic smooth muscle tissues were extracted using the RNA simple Total RNA kit (TIANGEN, Beijing, China), and the synthesis of first-strand cDNA was through applying the Prime Script RT Reagent Kit with gDNA Eraser (Takara, Dalian, Liaoning, China), based on the protocol offered by the manufacturer. Quantitative polymerase chain reaction (PCR) was conducted with specific primers by FastStart Universal SYBR Green Master Mix (Roche, Mannheim, Germany) on the 7500 Real Time PCR System (Applied Biosystems, Waltham, MA, USA). The expression of target genes relative to controls was analysed by the $\triangle \mathrm{CT}$ method. The sequences of the primers were used as follows:

ANO1 F-TGTACTTTGCCTGGCTTGGAGC
ANO1 R-CACCTGGCAATGCAGCCGTA
c-Kit F-CCTCATTGGCTTTGTGGTTGCAG
c-Kit R-ATGCGCCAAGCAGGTTCACAA
Gapdh F-CCATGGAGAAGGCCGGGG
Gapdh R-CAAAGTTGTCATGGATGACC

\section{Colonic Transit Experiment With Mimetic Fecal Pellet Propulsion}

The whole colon was eviscerated from control and DSS-colitis mice and immediately put into Krebs solution with oxygen. All feces in the colons were subsequently and gently flushed out using a syringe that was filled with Krebs solution and were transferred to a warm organ bath. The mesentery of the colon was pinned to the floor of the organ bath and constantly perfused with Krebs solution with oxygen $\left(37.2 \pm 0.5^{\circ} \mathrm{C}\right)$. Then a $6 \times 2.5 \mathrm{~mm}$ fecal-mimicked pellet was placed into the entrance of the proximal colon. The time for propagating the pellet along the entire colon from the oral to the anal end was recorded. 


\section{Colonic Migrating Motor Complexes Experiments}

Mice were sacrificed under general anaesthesia via overdose of the inhalant isoflurane followed by cervical dislocation. Next, the colon was exposed, removed quickly and placed into the Krebs solution that was continuously bubbling with a carbonated mixture $\left(5 \% \mathrm{CO}_{2}\right.$ and $95 \% \mathrm{O}_{2}$ ). The Krebs solution contained the following components (all concentrations in $\mathrm{mmol} / \mathrm{L}$ ): $\mathrm{NaCl}, 121.9$; $\mathrm{NaHCO}_{3}, 15.5 ; \mathrm{KCl}, 5.9 ; \mathrm{MgSO}_{4}, 1.2 ; \mathrm{KH}_{2} \mathrm{PO}_{4}, 1.2$; glucose, 11.5 ; and $\mathrm{CaCl}_{2}, 2.4$. The entire colon was fixed in a Sylgard base dish with impalpable steel pins. All fecal pellets in the colon were artificially expelled using a $1 \mathrm{~mL}$ injector. This procedure was performed with care to minimize intestinal damage. The empty colon was gently washed with $5 \mathrm{~mL}$ warm Krebs solution, and a glass capillary tube was inserted through the lumen and linked to an artificial fecal pellet. A silk thread (USP 5/0) was attached to about 10-15 mm of both ends of the colon. The mechanical activity of the CMMCs was recorded using an isometric force transducer (RM6240C; Chengdu Instrument Factory, Sichuan, China) that was linked to an amplifier device. A tension of $0.1 \mathrm{~g}$ was applied to the empty colon, which was equilibrated for at least 40 minutes before the addition of the experimental drugs.

\section{Preparation of Smooth Muscle Tissue and Isometric Tension Measurement}

The entire colon full of fecal pellets was isolated as described above. The colon was pinned to a Sylgard dish with the mucosa facing upwards; and the mucosa and submucosa were removed carefully under a dissecting microscope. Smooth muscle strips (approximately $2 \mathrm{~mm} \times 8 \mathrm{~mm}$ ) were obtained by cutting along the circular axis from the fresh smooth muscle tissue. A silk thread (USP 5/0) was attached to both ends of the muscle strips and attached along the circular axis into $10 \mathrm{~mL}$ organ baths that contained warm $\left(37^{\circ} \mathrm{C}\right)$ Krebs solution filled with $95 \% \mathrm{O}_{2}$ and $5 \% \mathrm{CO}_{2}$. The recording device was the same as that for the CMMCs above. A tension of 0.3 $\mathrm{g}$ was applied to the muscle strip, and it was equilibrated for at least 40 minutes before the recovery of its contraction activity.

\section{Intracellular Microelectrode Recording and Electrical Stimulation}

Based on the procedure above, smooth muscle tissue (approximately $20 \mathrm{~mm} \times 8 \mathrm{~mm}$ ) was isolated from the empty colon. The tissue was equilibrated for approximately 2 hours before the recording was started. The muscle tissue was maintained at $37 \pm$ $0.5^{\circ} \mathrm{C}$ through continuous perfusion with warm Krebs solution.
Experimental procedures were performed in the presence of nifedipine $(1 \mu \mathrm{M})$ to minimize the muscle contraction and maintain the cellular impalements. Circular muscle cells were inserted using glass microelectrodes (80-100 $\mathrm{M} \Omega$ ) that were filled with $\mathrm{KCl}$ for maintenance of the cellular impalements. Membrane potential (MP) was recorded using a Duo 773 (WPI Inc, Sarasota, FL, USA). Electrical field stimulation (EFS) was administered under a consistent voltage, pulse width and duration $(50 \mathrm{~V}, 0.5$ milliseconds, and 5 seconds) using a square-wave stimulator (YC-2 stimulator; Chengdu Instrument Factory). The sIJPs and fast inhibitory junctional potentials (fIJPs) of the smooth muscle were recorded in the presence and absence of various medicines, such as receptor blockers or agonists in the Krebs solution.

\section{Drugs}

DSS and atropine were purchased from Sigma-Aldrich. NGNitro-L-arginine methyl ester hydrochloride (L-NAME) and 5-nitro-2-(3-phenylpropylamino)benzoic acid (NPPB) were obtained from Tocris Bioscience (Ellisville, MO, USA).

\section{Statistical Methods}

The data are presented as the means $\pm \mathrm{SE}$. The analysis of data differences between groups was performed via one-way ANOVA, followed by Bonferroni's post hoc test or Student's unpaired $t$ test if needed. $P$-values less than 0.05 were thought to represent significant differences between groups, and n-values correspond to the number of animals used in the indicated experiments.

\section{Results}

\section{Dextran Sodium Sulfate-induced Colitis Mice Model}

DSS-induced colitis mice were used after 7 days, and 3\% DSS was administered via drinking water. The bodyweight significantly decreased in DSS-induced mice $(29.6 \pm 1.09 \mathrm{~g}$ for control mice; $19.6 \pm 0.65 \mathrm{~g}$ for colitis mice; $P<0.05 ; \mathrm{n}=20$ /group; Fig. 1A). After autopsy, the colons of the DSS-colitis mice were obviously shortened, with an average length of $29.7 \pm 0.6 \mathrm{~mm}(P<0.05$; n $=8$; Fig. $1 \mathrm{~B}$ and $1 \mathrm{C}$ ), compared with that of the control mice (ie, $49.3 \pm 1.6 \mathrm{~mm}, \mathrm{n}=8$ ). Furthermore, light microscopy of H\&Estained colonic sections displayed DSS colitis with the destruction of the epithelium, abnormal crypts, edema, and the infiltration of inflammatory cells ( $P<0.05 ; \mathrm{n}=7$ /group; Fig. $1 \mathrm{D}$ and $1 \mathrm{E})$, as well as hematochezia (not shown); the sections corresponded with a marked increase in disease activity index and histology score includ- 
A

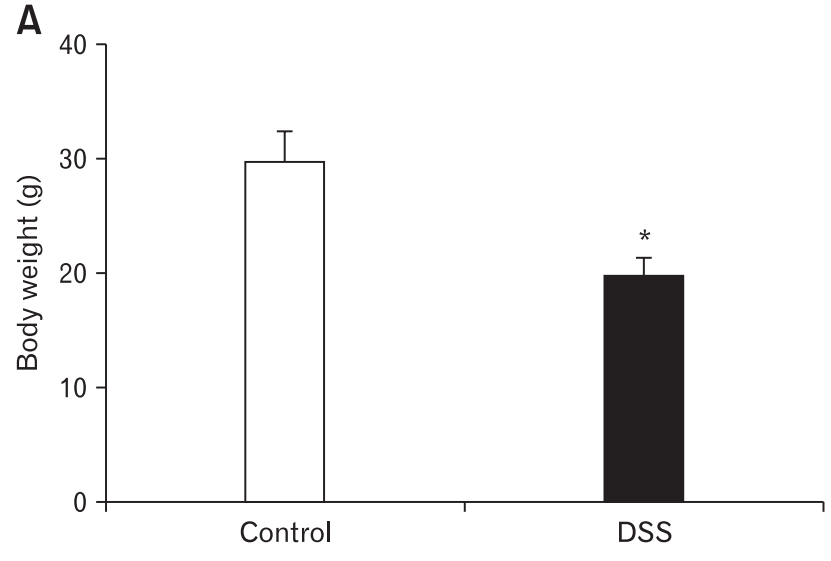

B

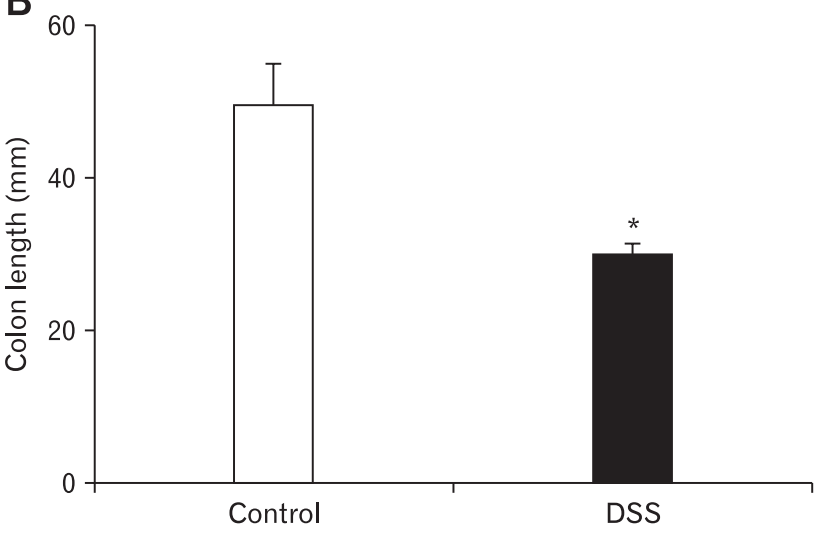

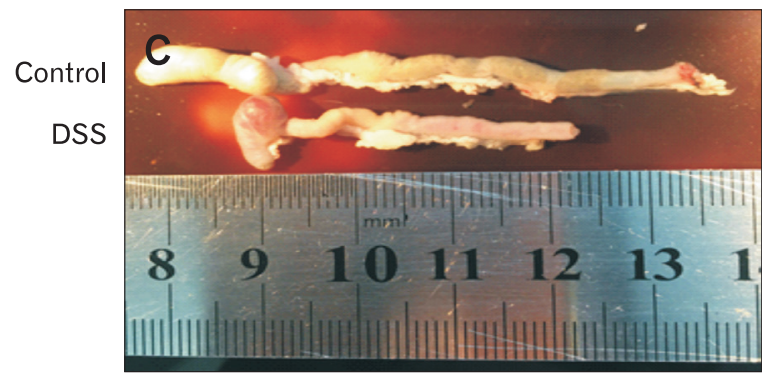

$\mathbf{F}$

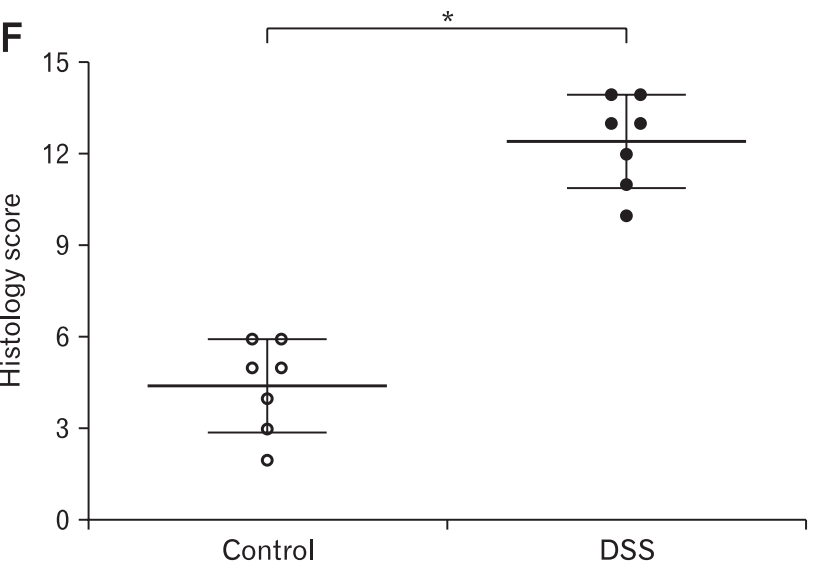

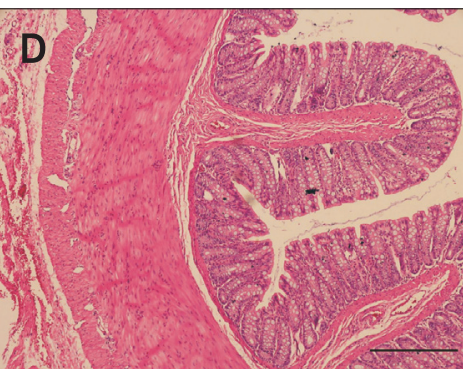

Control

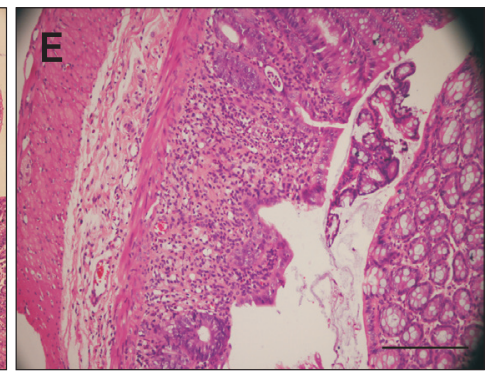

DSS

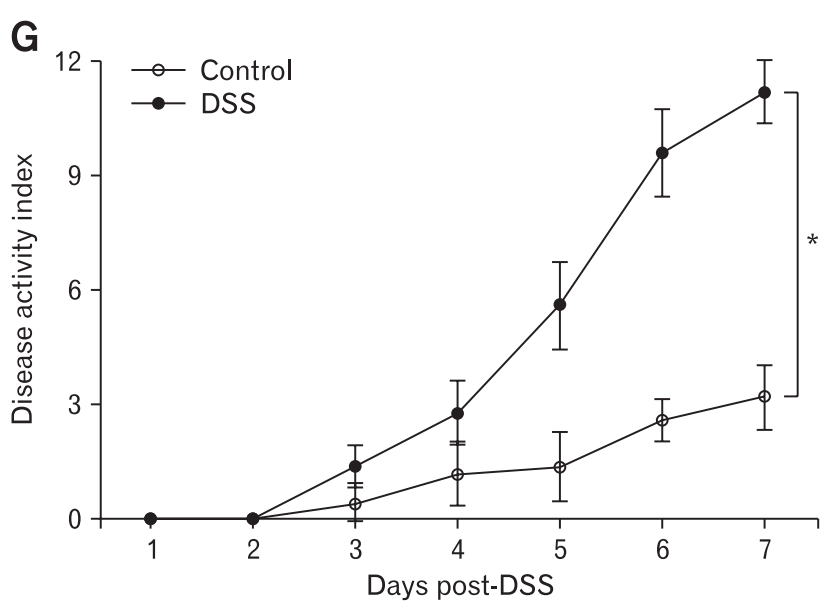

Figure 1. Changes in dextran sodium sulfate (DSS)-induced colitis and control mice. (A) Comparison of the bodyweight between control and DSS-colitis mice $\left({ }^{\star} P<0.05\right.$ vs control mice; $\mathrm{n}=20$ /group). (B, C) Comparison of the colon length between control and DSS-colitis mice ( ${ }^{\star} P$ $<0.05$ vs control mice; $n=8 /$ group). (D, E) Representative micrographs of colon H\&E from control and DSS-colitis mice 7 days after DSS treatment $(\mathrm{n}=7$ /group). Scale bars, $100 \mu \mathrm{m}$. (F) Histopathology scores from control and DSS-colitis colons $(\mathrm{n}=7 /$ group; $P<0.05$, statistical significance determined by unpaired Student's $t$ test). (G) Clinical disease activity index was a composite of weight change (percentage of day 0 ), stool score, and occult blood index ( $\mathrm{n}=7$ /group; ${ }^{*} P<0.05$, statistical significance determined by unpaired Student's $t$ test).

ing inflammatory infiltrates and overall tissue injury $(P<0.05$; $\mathrm{n}$ $=7$ /group; Fig. $1 \mathrm{~F}$ and $1 \mathrm{G})$.

\section{The Expression of c-KIT (Interstitial Cells of Cajal) and Anoctamin-1}

Based on the expression of the tyrosine kinase receptor (c-KIT) that reflects the identification of $\mathrm{ICC}$, ${ }^{22}$ we examined the expression 
A

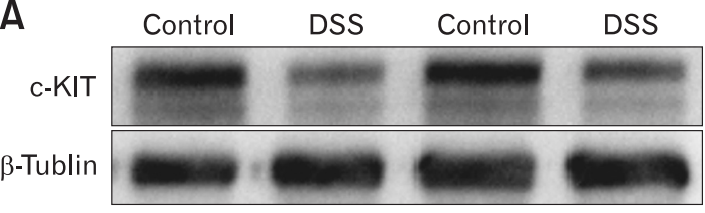

$145 \mathrm{kDa}$

$135 \mathrm{kDa}$

$55 \mathrm{kDa}$
B

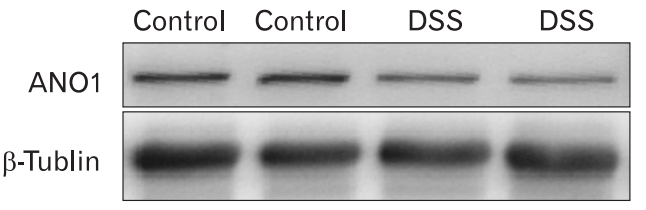

$114 \mathrm{kDa}$

$55 \mathrm{kDa}$
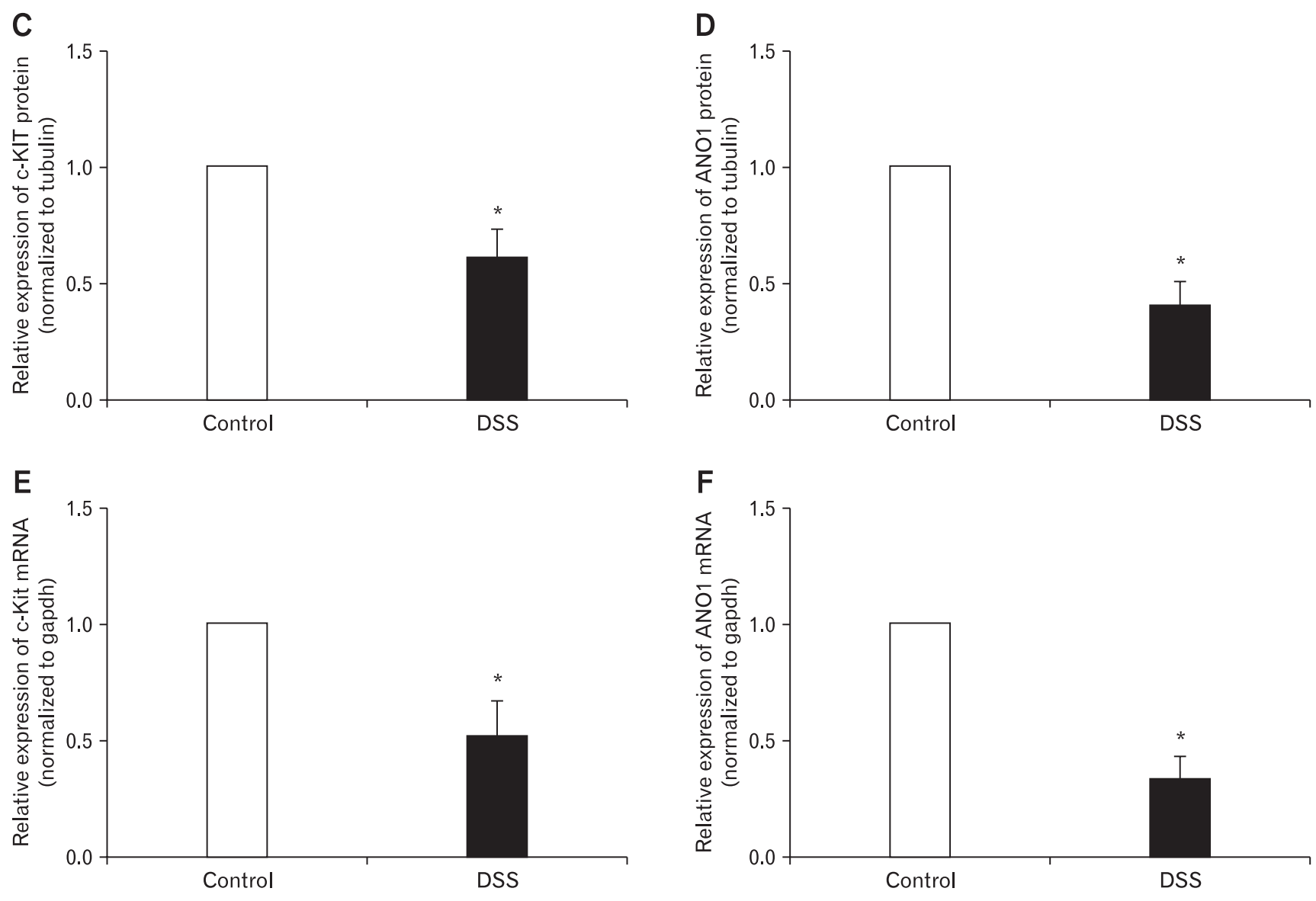

Figure 2. Expression of c-KIT and anoctamin-1 (ANO1) in colonic muscle layers of control and dextran sodium sulfate (DSS)-colitis mice. (A, C and B, D) Western blot analysis of c-KIT and ANO1 in control and DSS-colitis mice. The data were analysed using densitometric quantification (\% tubulin and normalized to data from control mice; $n=7,{ }^{*}<<0.05$ ). (E, F) Quantitative reverse transcription polymerase chain reaction analysis of c-Kit and ANO1 in colonic muscle layers from control and DSS-colitis mice. The data were normalized to gapdh and the data from control mice (c-Kit, $\mathrm{n}=7$; ANO1, $\mathrm{n}=7 ;{ }^{*} \mathrm{P}<0.05$ ).

of c-KIT in the colonic smooth muscle tissues of control and DSScolitis mice. The expression of c-KIT protein in colonic smooth muscle tissues of the DSS-colitis mice was obviously decreased to $60.86 \pm 4.8 \%(P<0.05 ; \mathrm{n}=7$ /group; Fig. $2 \mathrm{~A}$ and $2 \mathrm{C})$. In addition, the transcript level was detected via quantitative reverse transcription (RT)-PCR, which indicated that the gene expression of cKit decreased to $51.7 \pm 5.9 \%(P<0.05 ; \mathrm{n}=7$ /group; Fig. $2 \mathrm{E})$ in the DSS-colitis mice.

Additionally, considering that ICC highly expresses the ANO1 channel protein, ${ }^{11}$ we examined the gene and protein expression of
ANO1 via RT-PCR and western blot analysis. Compared with control mice, the expression of ANO1 protein in the DSS-colitis mice decreased to $41.0 \pm 4.2 \%(P<0.05 ; \mathrm{n}=7$ /group; Fig. $2 \mathrm{~B}$ and 2D). Meanwhile, the ANO1 (which encodes ANO1 channels) gene expression also decreased to $33.1 \pm 4.1 \%(P<0.05 ; \mathrm{n}$ $=7$ /group; Fig. $2 \mathrm{~F}$ ) in the DSS-colitis mice. These data show that the expression levels of c-KIT and ANO1 channels were downregulated in the colons of DSS-colitis mice. 
The Comparison of Colonic Migrating Motor Complexes Between Control and Dextran Sodium Sulfate-colitis Mice

To further certify the function of under-expressed ICC and ANO1 channels in the colons of colitis mice, CMMC experiments were performed to observe the differences between control mice and DSS-colitis mice. We observed that the DSS-colitis mice showed significantly different contraction frequencies and amplitudes in the proximal and distal colon compared with the regular and consistent contractions of the control mice. In addition, the fluctuating range of the contraction amplitude in DSS colitis indicated very irregular contraction in colonic transit (Fig. 3A and 3B). These results indicate that the disordered transmission in DSS-colitis mice may result from the downregulation of ICC and ANO1 channels.

We also examined the propagation time of mimetic pellets along the whole colons from the proximal to distal end to observe whether the colitis mice showed slow transit. The total moving time for the pellet from the proximal to distal ends of the colons was recorded. The transit time of the colon in control mice was $718 \pm 28$ seconds with the velocity of $0.074 \pm 0.01 \mathrm{~mm} / \mathrm{sec}(\mathrm{n}=8$; Fig. $3 \mathrm{C}$ and $3 \mathrm{D})$. However, the transit time of the DSS-colitis mice averaged $551 \pm$ 15 seconds with the velocity of $0.055 \pm 0.01 \mathrm{~mm} / \mathrm{sec}(\mathrm{n}=8$; Fig. $3 \mathrm{C}$ and $3 \mathrm{D})$. Although the entire colonic transit time of DSS-colitis mice was considerably less than that of control mice $(P<0.05$; n $=8$ /group; Fig. 3C), the velocity for the DSS-colitis mice was far slower than that for control mice on account of the shorter length of the colitis colon than the colon of the control mice $(P<0.05$; n $=8$ /group; Fig. 1D). These data indicate that colonic transits are delayed in the DSS-colitis mice.

\section{The Effect of Anoctamin-1 Channel Antagonist on Colonic Migrating Motor Complexes and Colonic Smooth Muscle Contraction}

To further study the effect of under-expressed ICC and ANO1 channels on CMMCs, NPPB ( $3 \mu \mathrm{M}$; ANO1 channel antagonist)

\section{A}

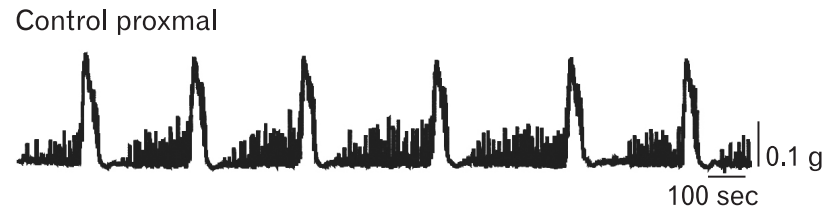

DSS proximal
B

Control distal

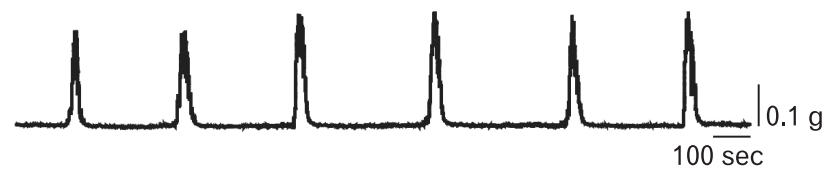

DSS distal
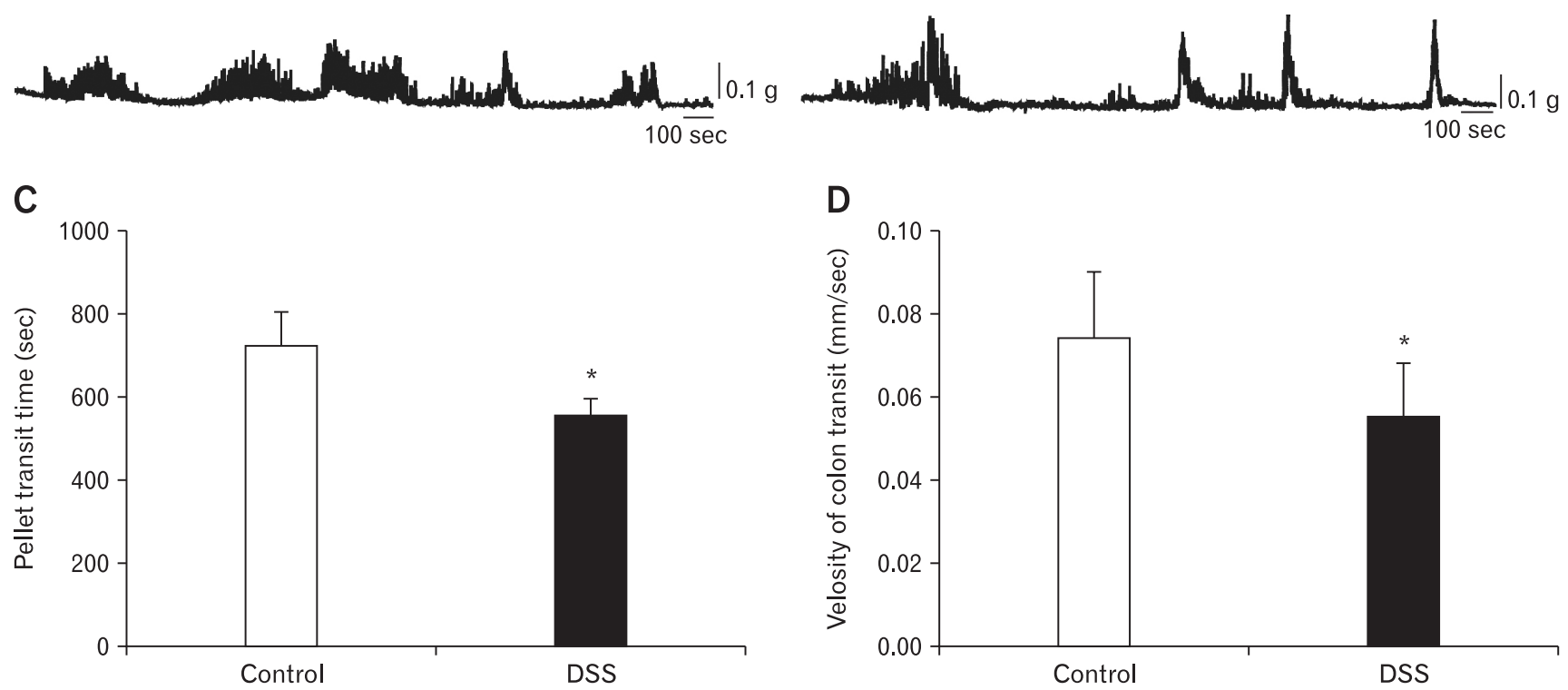

Figure 3. The comparison of colonic transit between control mice and dextran sodium sulfate (DSS)-colitis mice on colonic migrating motor complexes (CMMCs). (A) The comparison of contraction frequencies and amplitudes in proximal colons between control mice and DSS-colitis mice; $\mathrm{n}=7$ mice/group. (B) The comparison of distal colons in colonic transit between control mice and DSS-colitis mice; $n=7 /$ group. (C, D) Summary of the pellet transit time and the colonic transit velocity in control and DSS-colitis mice $\left({ }^{\star} P<0.05\right.$ vs control mice; $\left.\mathrm{n}=8 / \mathrm{group}\right)$. 
was used in the CMMCs and colonic smooth muscle contraction experiments. We found that the CMMCs of colitis in the proximal colon, which was treated with NPPB, exhibited obvious drug action from $100 \%$ in the controls (before the application of NPPB) to $56.4 \pm 2.9 \%$ compared with the control mice and more significantly decreased to $39.2 \pm 3.9 \%$ in the DSS-colitis mice $\left({ }^{*} P<\right.$ $0.05 ; \mathrm{n}=7$; Fig. $4 \mathrm{~A}$ and $4 \mathrm{C}$ ). The relative change of contractions in colons was attenuated in the DSS-colitis mice $\left({ }^{\#} P<0.05\right.$; Fig. $4 \mathrm{C})$. However, in the distal colons, although NPPB reduced the contractions of the CMMCs in the colitis mice from $100 \%$ in the controls to $58.2 \pm 2.1 \%$, NPPB induced significantly reduced contractions in the control mice and decreased the amplitude to 33.7 $\pm 3.7 \%\left({ }^{*} P<0.05 ; \mathrm{n}=8\right.$ /group; Fig. $4 \mathrm{~B}$ and $\left.4 \mathrm{D}\right)$. Therefore, in distal colons, the relative change of contractions in colons was still attenuated in the DSS colitis mice $\left({ }^{\#} P<0.05\right.$; Fig. 4D).

In the following muscle strip contraction experiment, NPPB still significantly decreased the contractions to $31.8 \pm 3.9 \%\left({ }^{\star} P\right.$ $<0.05 ; \mathrm{n}=5$; Fig. $4 \mathrm{E}$ and $4 \mathrm{G})$ in proximal colons and $47.8 \pm$ $4.2 \%\left({ }^{\star} \mathrm{P}<0.05 ; \mathrm{n}=5\right.$; Fig. $4 \mathrm{~F}$ and $\left.4 \mathrm{H}\right)$ in distal colons of control mice. However, the contractions of proximal and distal colonic smooth muscles in DSS-colitis mice were only reduced to $82.6 \pm$ $2.5 \%\left({ }^{\star} P<0.05 ; \mathrm{n}=5\right.$; Fig. $4 \mathrm{E}$ and $\left.4 \mathrm{G}\right)$ and $76.8 \pm 4.2 \%\left({ }^{\star} P\right.$ $<0.05 ; \mathrm{n}=5$; Fig. $4 \mathrm{~F}$ and $4 \mathrm{H})$, respectively, in the presence of NPPB. The colitis colonic smooth muscles were less sensitive to ANO1 channel antagonists $\left({ }^{\#} P<0.05\right.$ in proximal colons, ${ }^{\#} P$ $<0.05$ in distal colons; Fig. $4 \mathrm{G}$ and $4 \mathrm{H}$ ). The effect of NPPB on CMMCs and colonic smooth muscle contractions were less susceptible in both the proximal and distal colons of DSS-colitis mice ${ }^{\#} P<0.05$; Fig. 4C, 4D and 4G, 4H), which indicated that ANO1 channels were functionally downregulated in the colons of the DSS-colitis mice.

\section{The Effect of L-NAME on Colonic Migrating Motor Complexes and Colonic Smooth Muscle Contraction}

Subsequently, L-NAME (100 $\mu \mathrm{M})$, a nonspecific inhibitor of NOS, was also used in the present study. Previous studies showed the released $\mathrm{NO}$ in the $\mathrm{NO}$ signalling pathway played pivotal roles in activating ICC and generating consecutive smooth muscle relaxation. ${ }^{17}$ Next, we observed that the effects of L-NAME were completely opposite of those observed with NPPB treatment. LNAME markedly enhanced CMMCs to $138.0 \pm 3.3 \%$ in the proximal colon of the DSS-colitis mice and $116.1 \pm 2.8 \%$ in the distal parts of the DSS-colitis mice $\left({ }^{*} P<0.05 ; n=7\right.$ /group; Fig. $5 \mathrm{~A}[\mathrm{~b}] / \mathrm{C}$ and $5 \mathrm{~B}[\mathrm{~b}] / \mathrm{D})$. However, the excitatory effect of $\mathrm{L}$ NAME for the control mice appeared significantly prominent, the CMMCs in the proximal colon increased from $100 \%$ in the controls to $172.3 \pm 4.6 \%$, and that in the distal colon increased to $145.1 \pm 4.4 \%\left({ }^{*} P<0.05 ; \mathrm{n}=7 /\right.$ group; Fig. $5 \mathrm{~A}[\mathrm{a}] / \mathrm{C}$ and $5 \mathrm{~B}[\mathrm{a}] / \mathrm{D})$. Clearly, the effects of L-NAME on CMMCs were considerably more significant in the control mice than that in the DSS-colitis colon ( ${ }^{\#} \mathrm{P}<0.05 ; \mathrm{n}=7$ /group; Fig. 5C and 5D).

The smooth muscle contractions were also analysed before and after the addition of L-NAME. Apparently, L-NAME significantly potentiated the spontaneous contractions to $163.4 \pm 3.5 \%$ and $131.6 \pm 3.9 \%$ in the proximal colons of the control and DSScolitis mice, respectively $\left({ }^{*} P<0.05 ; \mathrm{n}=7\right.$ /group; Fig. $5 \mathrm{E}$ and $5 \mathrm{G})$. The relative change in the contractions of colons was weakened in the DSS-colitis mice $\left({ }^{\#} P<0.05\right.$; Fig. 5G). In distal colons, L-NAME obviously increased the smooth muscle contractions to $134.6 \pm 2.0 \%$ and $115.8 \pm 2.7 \%\left({ }^{*} P<0.05 ; \mathrm{n}=7\right.$ /group; Fig. $5 \mathrm{~F}$ and $5 \mathrm{H})$, respectively, in the control and DSS-colitis mice, which indicated that the colonic smooth muscles in control mice were more sensitive to L-NAME than the colonic smooth muscles in colitis mice $\left({ }^{\#} \mathrm{P}<0.05 ; \mathrm{n}=7\right.$ /group; Fig. $\left.5 \mathrm{H}\right)$. These results further illustrate that the function of $\mathrm{NO}$ channels is downregulated in the colons of the DSS-colitis mice, which may contribute to the colonic transit disorder.

\section{The Effect of NPPB on Colonic Membrane Potential}

The excitatory effects of ANO1 channels in ICC for smooth muscle contraction may be attributed to the depolarization of SMCs. ${ }^{23}$ In this study, intracellular electronic recordings were applied to explore the effects of ANO1 channels on MP. NPPBinduced hyperpolarization reaction was weaker in colonic SMCs of the DSS-colitis mice in the proximal colon with a mean amplitude of $6.9 \pm 0.5 \mathrm{mV}$ compared with colonic SMCs of control mice (ie, $9.8 \pm 0.4 \mathrm{mV} ; P<0.05 ; \mathrm{n}=7$ /group; Fig. $6 \mathrm{~A}$ and $6 \mathrm{C}$ ). The NPPB-induced hyperpolarization in the distal colon was more insensitive than that in the proximal colon. The average amplitudes of the DSS-colitis mice in the distal colon decreased to $4.0 \pm 0.2$ $\mathrm{mV}$, and that of the control mice was $7.2 \pm 0.3 \mathrm{mV}(P<0.05 ; \mathrm{n}$ $=7$ /group, Fig. $6 \mathrm{~B}$ and $6 \mathrm{D})$. These results illustrate that the functionally downregulated ANO1 channels play a pivotal role in the depolarization reaction of colonic SMCs in DSS-colitis mice, which results in the attenuation of SMC excitability.

\section{Changes in Electrical Field Stimulation-induced Slow Inhibitory Junctional Potentials in the Dextran Sodium Sulfate-colitis Colons}

It has been reported that nitric neurotransmitters released by 
A

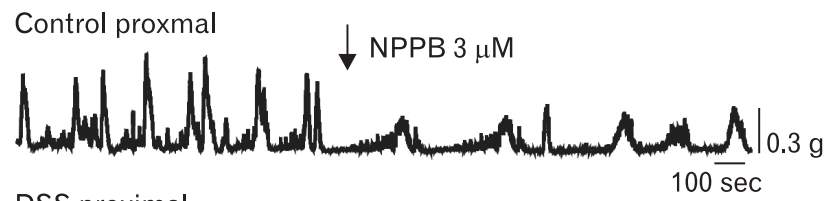

DSS proximal

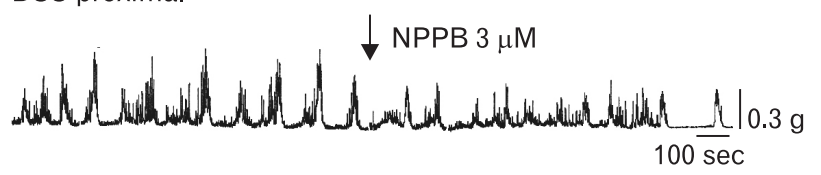

C

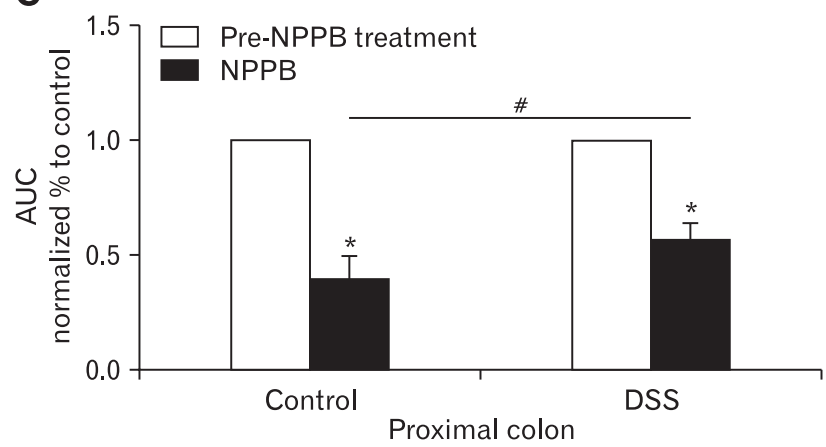

E
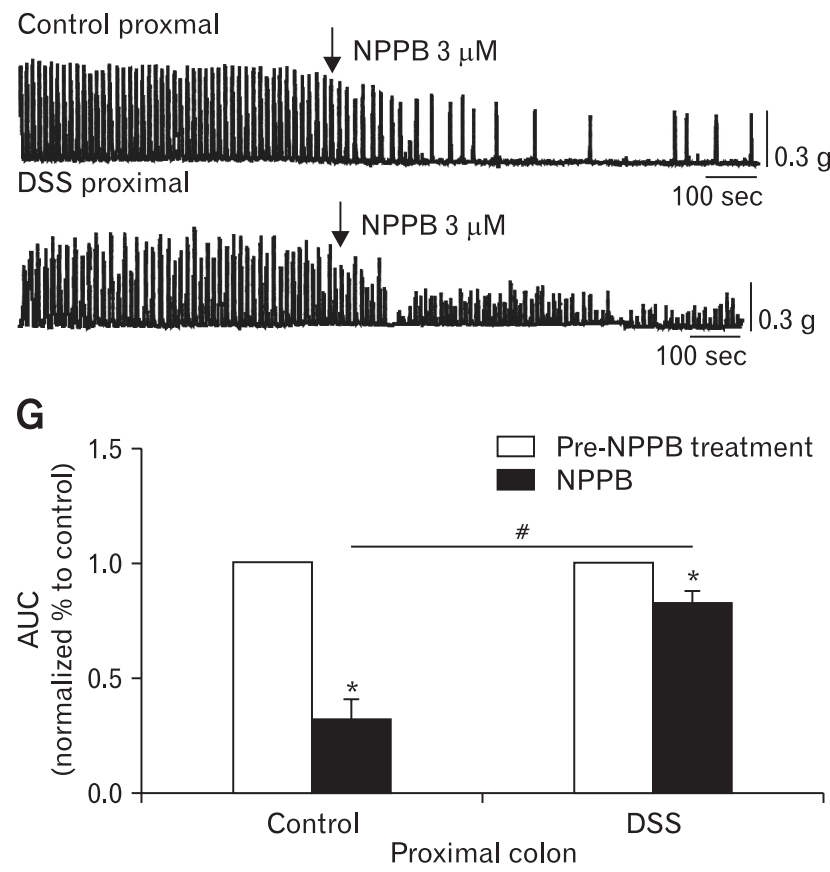

B

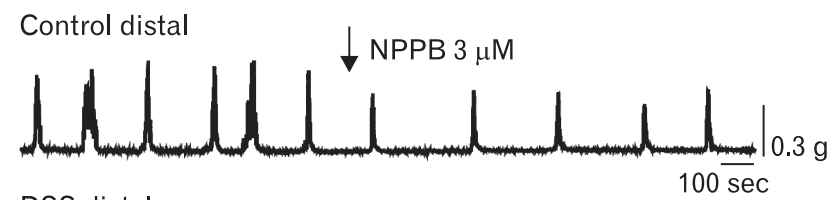

DSS distal

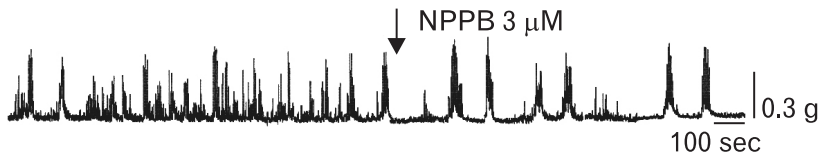

D

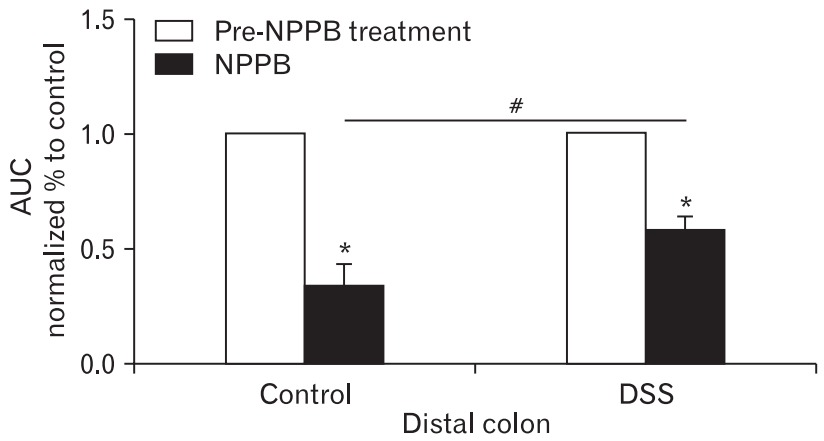

F

Control distal

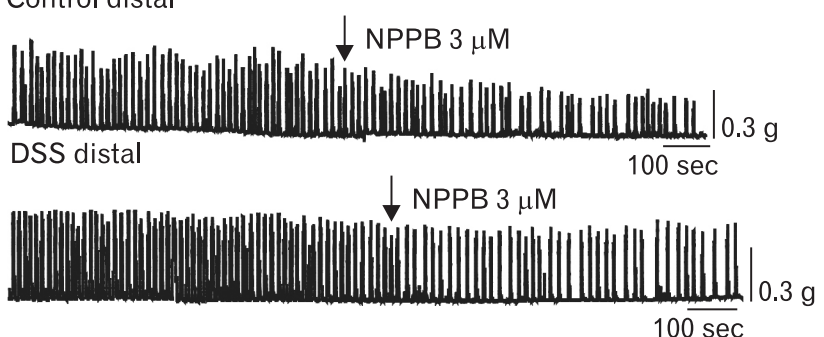

H

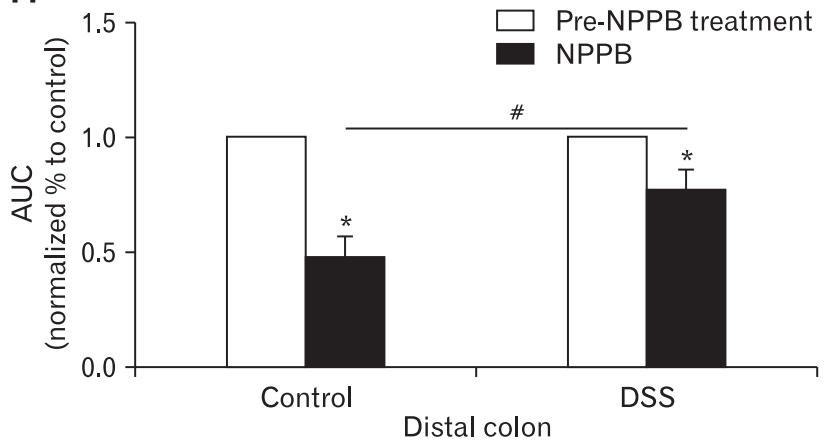

Figure 4. Contractile responses to the anoctamin-1 antagonist (NPPB) in the colonic migrating motor complexes (CMMCs) and colonic muscles of control and dextran sodium sulfate (DSS)-colitis mice. (A, B) The inhibitory effects of NPPB $(3 \mu \mathrm{M})$ on CMMCs in the proximal and distal colons of both control and DSS-colitis mice. (C, D) Summary data of the area under the curve (AUC) at 400 seconds. The data were normalized to the control (before the application of $\mathrm{NPPB}$ ) ( $\mathrm{n}=7$ /group; ${ }^{*} P<0.05$ vs control; ${ }^{\#} \mathrm{P}<0.05$ vs control mice). (E, F) Response of colonic smooth muscle contractions to NPPB $(3 \mu \mathrm{M})$ in the proximal and distal colons of both control and DSS-colitis mice. (G, H) Summary of the contractile responses to NPPB, as indicated by the AUC at 400 seconds, in the colonic muscles of control and DSS-colitis mice. The data were normalized to the control value (before the application of NPPB) ( $\mathrm{n}=5$ /group; ${ }^{*} P<0.05$ vs control; ${ }^{\#} P<0.05$ vs control mice). 
A

[a] Control proxmal

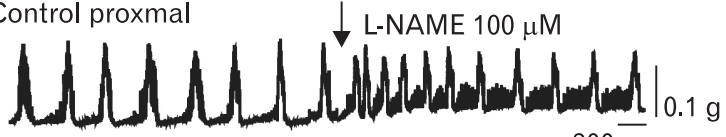

[b]
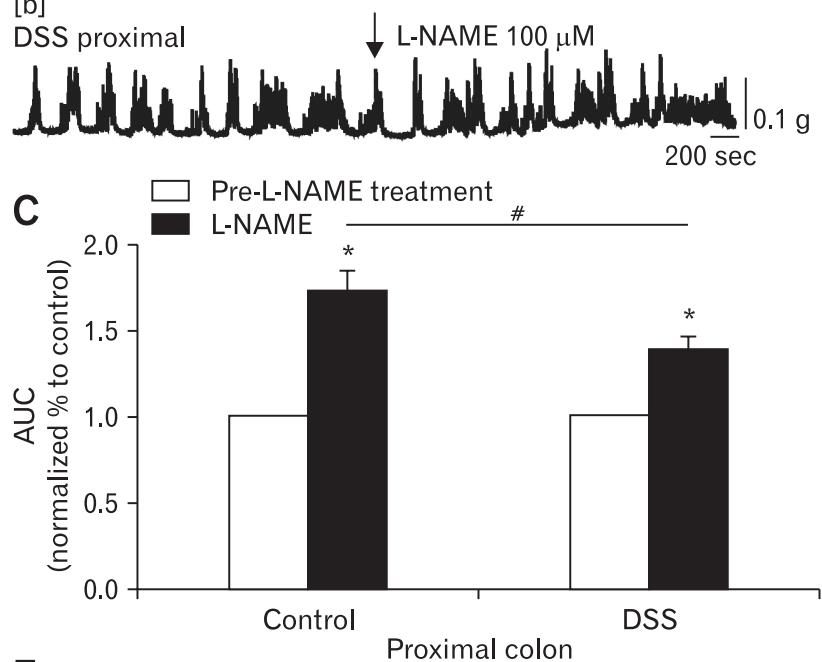

E
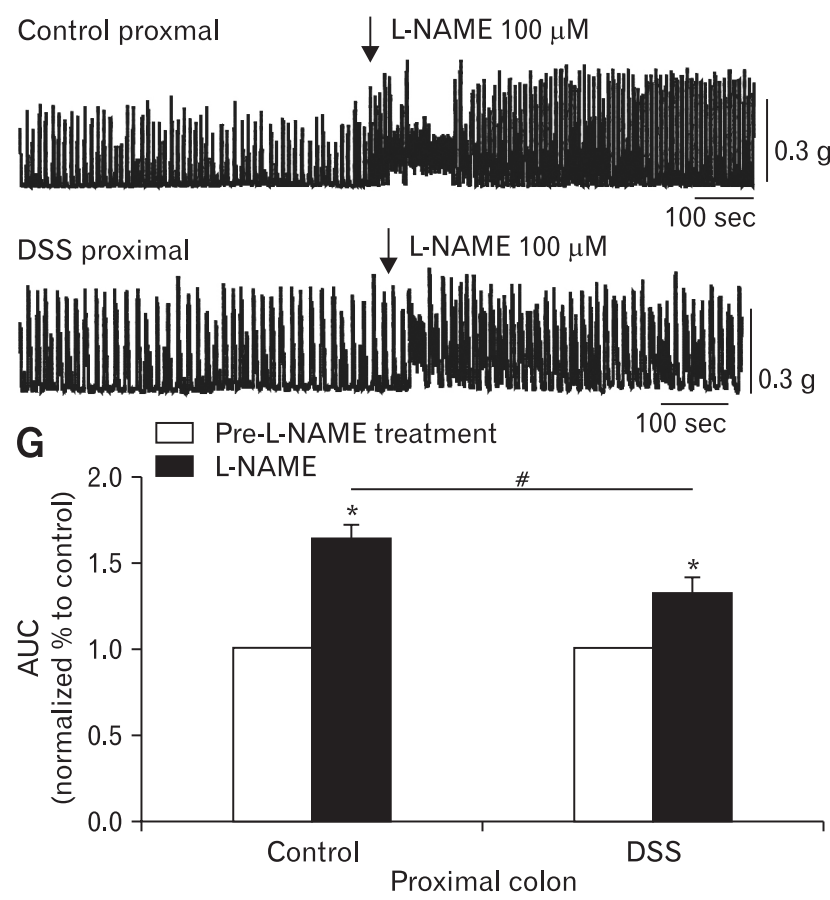

B

[a]

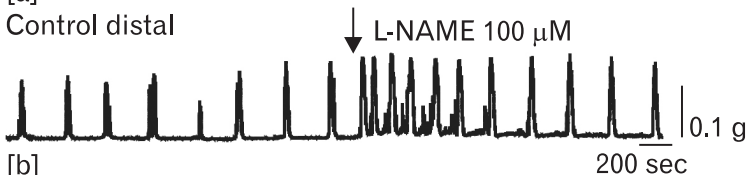

[b]

DSS distal
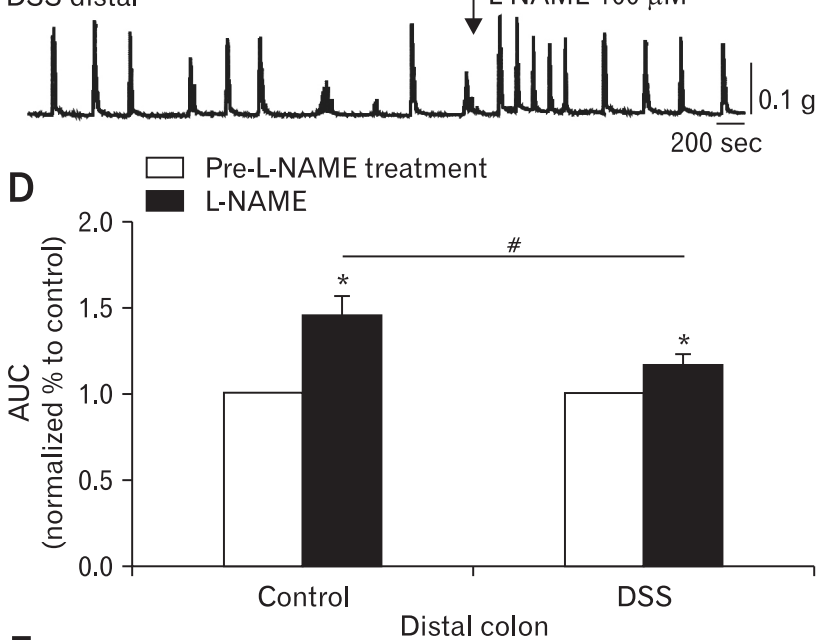

F

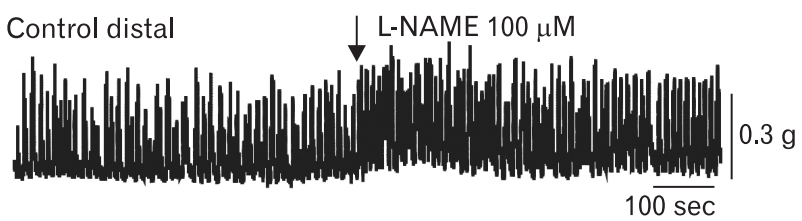

DSS distal
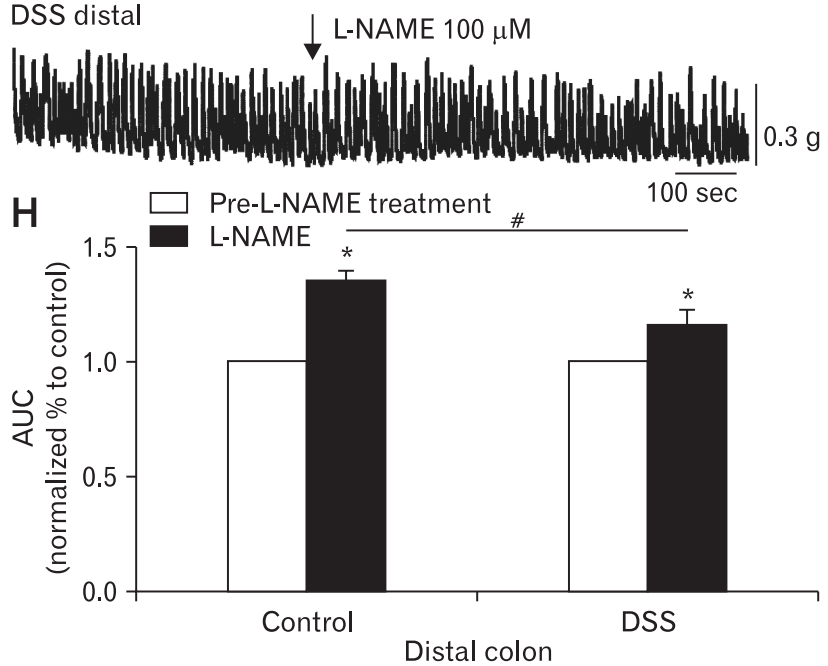

Figure 5. Contractile responses to the nitric oxide antagonist (L-NAME) in the colonic migrating motor complexes (CMMCs) and colonic muscles of control and dextran sodium sulfate (DSS)-colitis mice. (A, B) Responses of CMMCs to the L-NAME (100 $\mu$ M) in the proximal and distal colons of both control and DSS-colitis mice. (C, D) Summary of the CMMC responses of L-NAME, as indicated by the area under the curve (AUC) at 400 seconds in the control and DSS-colitis mice. The data were normalized to the control value (before the application of LNAME) (n = 7/group; ${ }^{*} P<0.05$ vs control; ${ }^{*} P<0.05$ vs control mice). (E, F) Response of colonic smooth muscle contractions to L-NAME $(100 \mu \mathrm{M})$ in the proximal and distal colons of both control and DSS-colitis mice. $(\mathrm{G}, \mathrm{H})$ Summary of the data showing contractile responses to LNAME as indicated by the AUC at 400 seconds in the colonic muscles of control and DSS-colitis mice. The data were normalized to control (before the application of L-NAME) ( $\mathrm{n}=7 /$ group; ${ }^{*} \mathrm{P}<0.05$ vs control; ${ }^{*} \mathrm{P}<0.05$ vs control mice). 
A

Control proxmal
B

Control distal

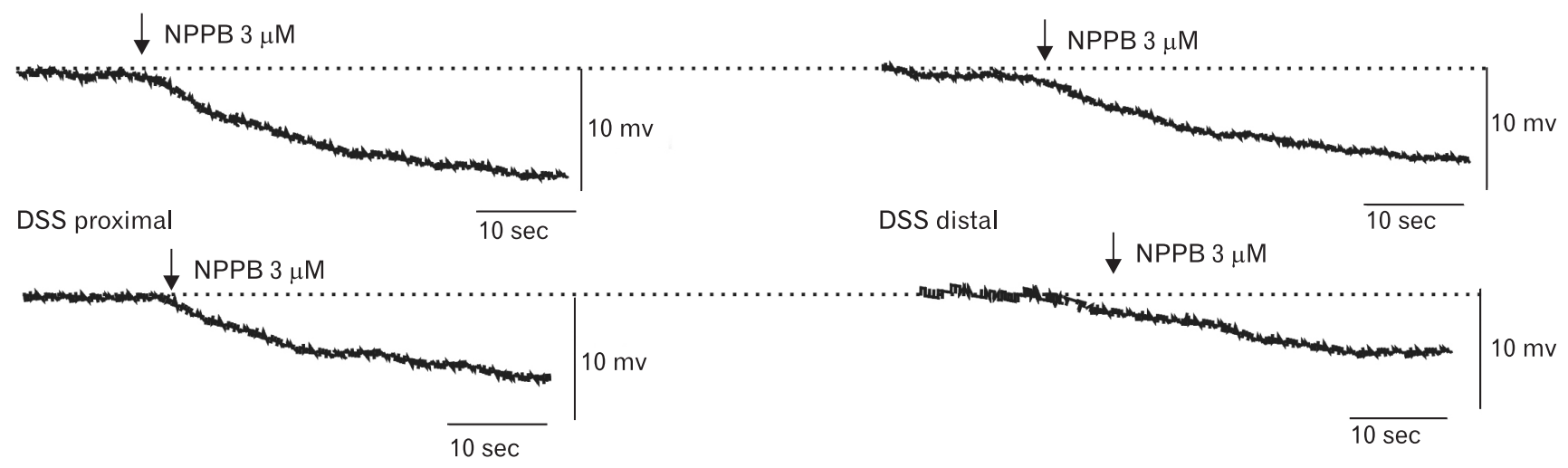

C

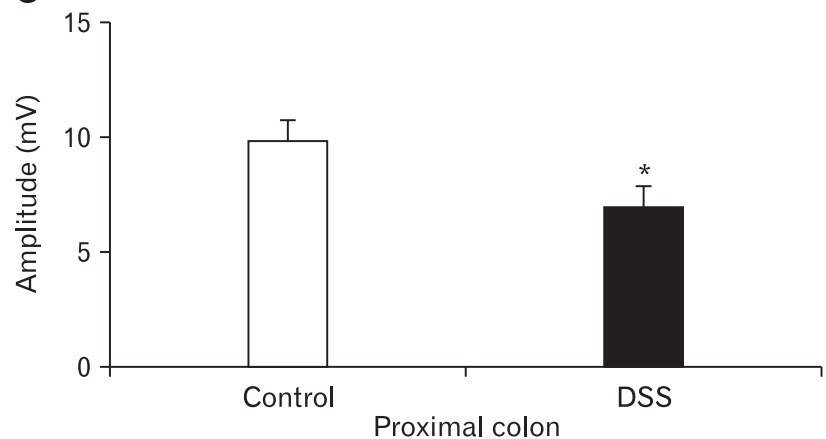

D

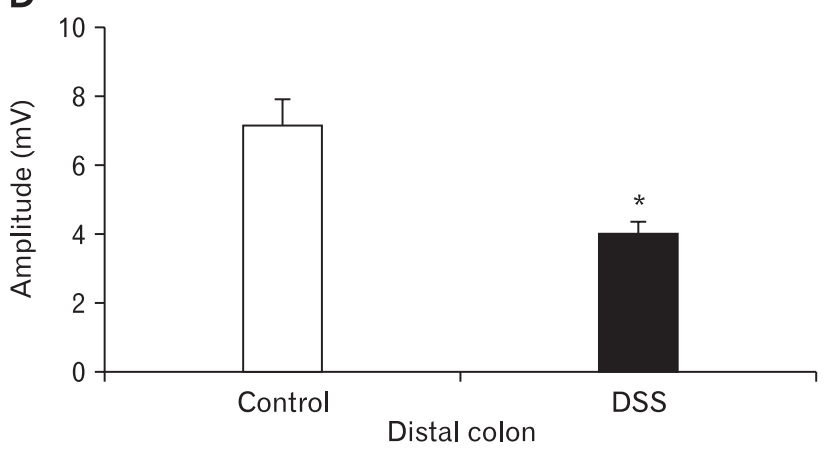

Figure 6. The responses to the anoctamin-1 antagonist (NPPB) in colonic smooth muscle cells of control and dextran sodium sulfate (DSS)-colitis mice. (A, B) The responses of the membrane potentials to the NPPB in proximal and distal colonic smooth muscle cells (NPPB, $3 \mu \mathrm{M}$, arrow). (C, D) Summary of the data showing the average effects of NPPB on membrane potentials in both control and DSS-colitis colonic SMCs ( $\mathrm{n}=7 /$ group; $\left.{ }^{*} P<0.05\right)$.

enteric motor neurons and expressed on ICC play an important role in the neural regulation of GI motility. ${ }^{24,25}$ Therefore, in the subsequent experiments, the function of ICC and nitric neural regulation were further studied in DSS-colitis mice. EFS induced biphasic IJPs in control colonic muscles, consisting of a fast hyperpolarization (fIJP), following with a more stable hyperpolarization reaction (sIJP) that continued till the stimulus ended. ${ }^{26,27}$

In the following experiments, the amplitudes of sIJPs were recorded in control and DSS-colitis mice. In the proximal colon of the control mice, EFS (50 V; 3, 6, and $9 \mathrm{~Hz} ; 5$ seconds) induced a continuous hyperpolarization after the fIJPs, and the average amplitudes of sIJPs were $3.3 \pm 0.3,7.6 \pm 0.4$, and $13.7 \pm 0.4 \mathrm{mV}$ (n $=7$; Fig. $7 \mathrm{~A}[\mathrm{a}]$ and $7 \mathrm{C}$ ), respectively. However, the amplitudes of sIJPs during the stimulations of 3,6 , and $9 \mathrm{~Hz}$ in the colitis mice were $1.3 \pm 0.2,5.0 \pm 0.3$, and $10.0 \pm 0.6 \mathrm{mV}$, respectively, which became smaller than the values for control mice $(P<0.05 ; \mathrm{n}=7$; Fig. 7A[b] and 7C). In addition, we also compared the amplitudes of distal colonic tissues between the control and DSS-colitis mice. The average amplitudes of the sIJPs were still smaller in the distal colon of DSS-colitis mice than in the control mice $(2.0 \pm 0.3,5.1$ \pm 0.2 , and $10.7 \pm 0.4 \mathrm{mV}$ in the control colon, $\mathrm{n}=7 ; 1.1 \pm 0.07$, $3.2 \pm 0.25$, and $8.6 \pm 0.29 \mathrm{mV}$ in the distal colon, $\mathrm{n}=7 ; P<$ 0.05 , Fig. $7 \mathrm{~B}$ and $7 \mathrm{D})$. These results confirm that the sIJP elicited by NO neurotransmitters in the colitis colon appeared weaker compared with that in the control mice; this phenomenon may result from the downregulation of ICC and ANO1 channels. Therefore, we explored the functional role of ICC through analysing sIJPs in both normal and colitis mice.

\section{Changes in Nitric Oxide-dependent Slow Inhibitory Junctional Potentials via Blocking the Fast Inhibitory Junctional Potentials in the Dextran Sodium Sulfate- colitis Colons}

To further explore the mechanism of colonic transmission dis- 
A

[a]

Control proxmal

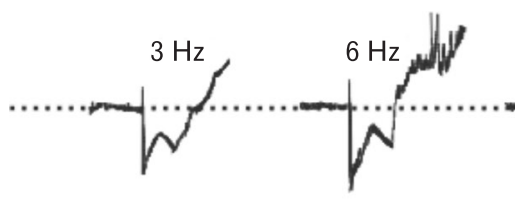

[b]

DSS proximal
B

[a]

Control distal

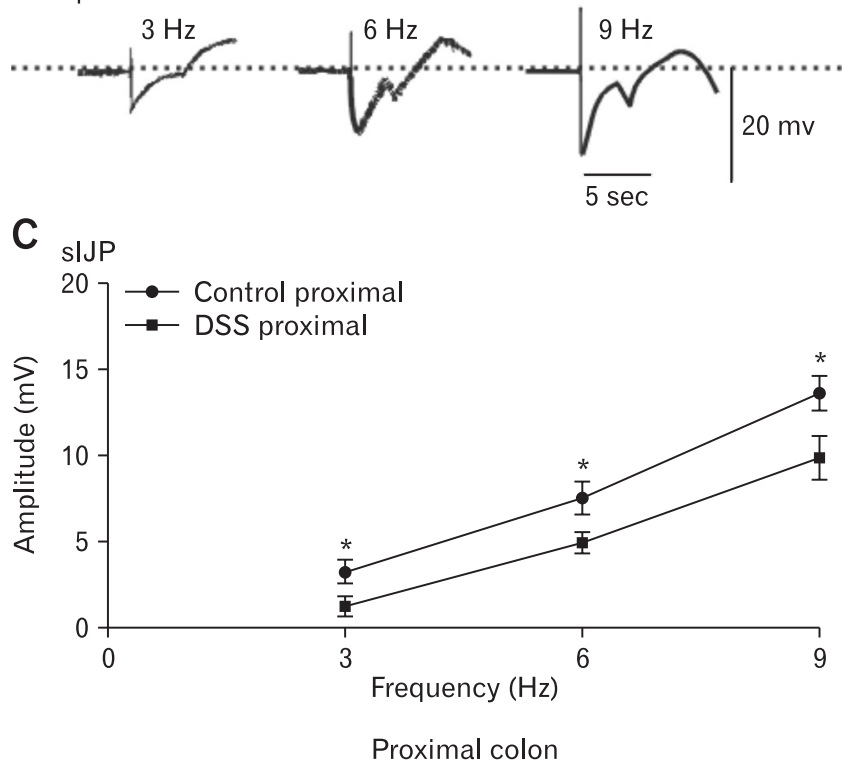

[b]

DSS distal
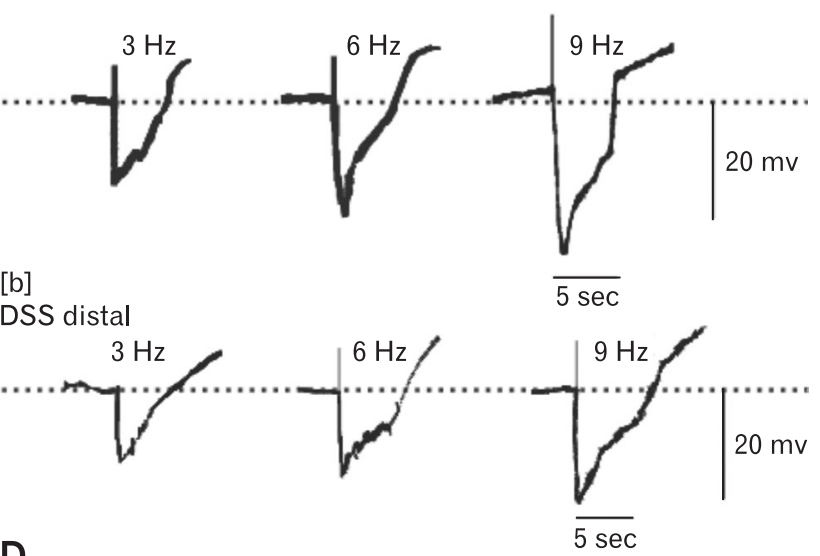

$D_{\text {SIJP }}$

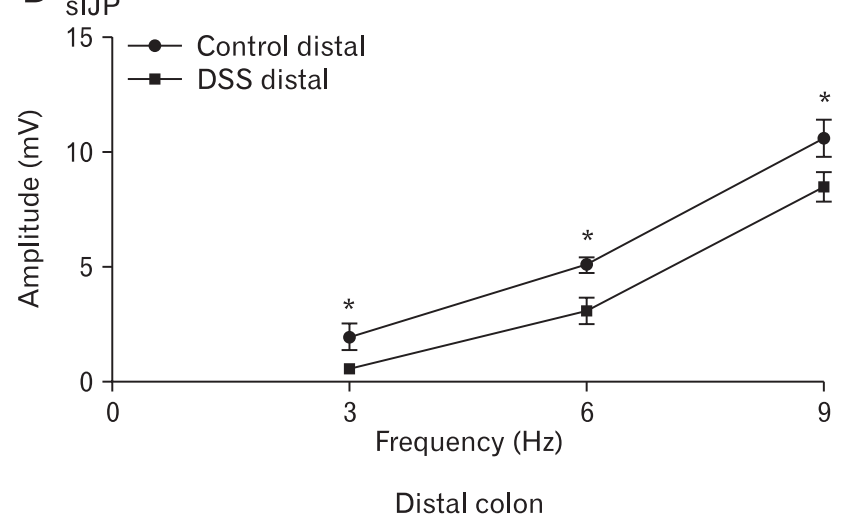

Figure 7. Slow junctional potentials elicited by electrical field stimulation (EFS) in proximal and distal colonic muscles from control and dextran sodium sulfate (DSS)-colitis mice. (A, B) Raw traces of EFS-elicited slow inhibitory junctional potentials (sIJPs) in the colonic muscles of control and DSS-colitis mice (3, 6, and $9 \mathrm{~Hz}$ for 5 seconds; black bars in each panel). (C, D) Summary of the data showing the average amplitude of sIJPs in the proximal and distal colonic muscles of control and DSS-colitis mice (in the proximal colon, $\mathrm{n}=7 /$ group, ${ }^{*} P<0.05$; in the distal colon, $\mathrm{n}=$ 7/group, $\left.{ }^{*} P<0.05\right)$.

order via downregulation of the ICC and ANO1 channel in the DSS-colitis mice, fIJP, which was induced by purine and released from enteric motor neurons, was blocked by atropine $(1 \mu \mathrm{M})$ and MRS2500 (1 $\mu \mathrm{M})$, which obviously reduced its amplitude but did not affect the sIJPs at different EFS frequencies. In both control and DSS-colitis colonic smooth muscles, the amplitudes of sIJPs in colonic muscles of the DSS-colitis mice were still smaller than that in the proximal colon of control mice (ie, $5.2 \pm 0.6,9.1 \pm 0.6$, and $14.6 \pm 0.5 \mathrm{mV}$, respectively, in the colons of control mice; $2.1 \pm 0.3$, $5.9 \pm 0.4$, and $7.8 \pm 0.3 \mathrm{mV}$, respectively, in the colons of DSScolitis mice; $P<0.05 ; \mathrm{n}=6$ /group; Fig. $8 \mathrm{~A}$ and $8 \mathrm{C}$ ). Meanwhile, the amplitudes for the distal colon were also compared in both control and colitis mice. The amplitudes of sIJPs in the distal colonic muscles of the DSS-colitis mice remained weaker than those in the control colon (ie, $3.5 \pm 0.2,5.5 \pm 0.4$, and $10.2 \pm 0.4 \mathrm{mV}$ ), and in the distal colon of the DSS-colitis mice, the mean amplitudes were separately $1.4 \pm 0.2,3.3 \pm 0.3$, and $7.2 \pm 0.3 \mathrm{mV}(P<0.05 ; \mathrm{n}$ $=6 /$ group; Fig. $8 \mathrm{~B}$ and $8 \mathrm{D})$. Considering that $\mathrm{ICC}$ is viewed as an important mediator of $\mathrm{NO}$ neurotransmitter, these results clearly illustrate that the reaction of ICC and ANO1 channels to NO neurotransmitters is downregulated in the colonic smooth muscles of DSS-colitis mice.

\section{Discussion}

To date, literature has been reported regarding the mechanism of colonic transit obstruction in UC that is elicited by pro-inflammatory cytokines of the mucosa and submucosa layers. ${ }^{28,29}$ However, 
A

Control proxmal (atropine and MRS2500)
B

Control distal (atropine and MRS2500)

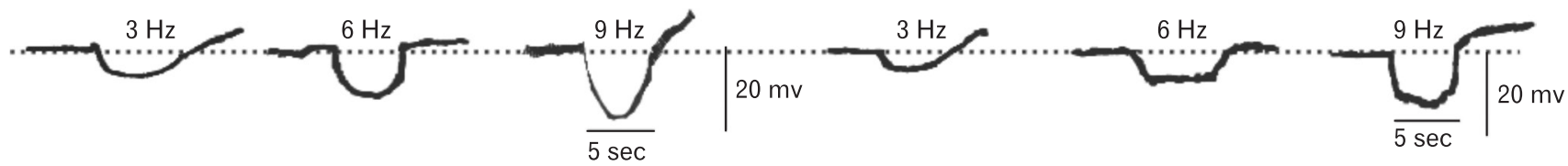

DSS proximal

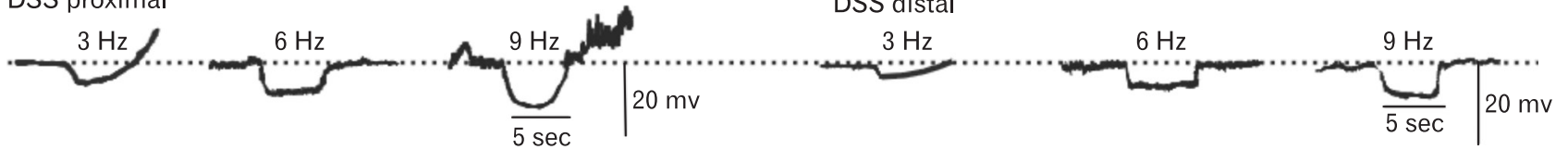

$C_{\text {SIJP }}$

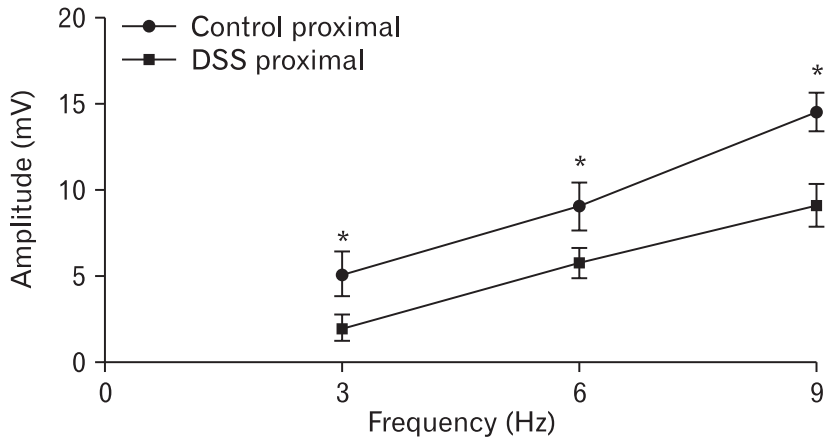

Proximal colon
$D_{\text {sIJP }}$

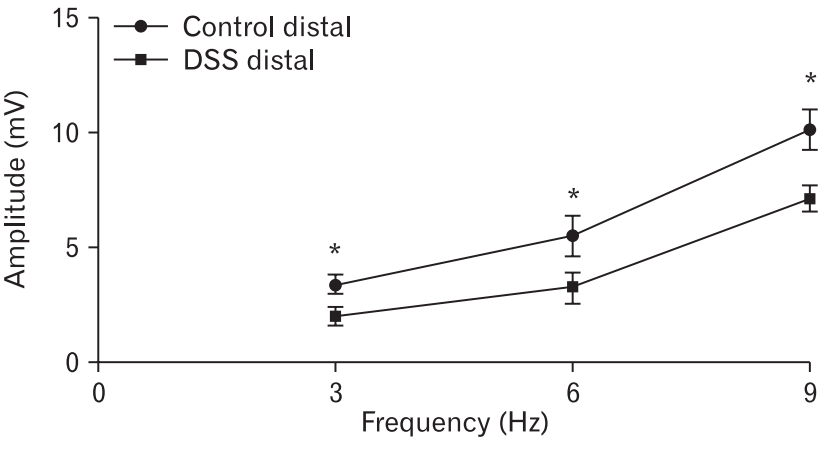

Distal colon

Figure 8. Slow junctional potentials elicited by electrical field stimulation (EFS) with inhibition of the fast inhibitory junctional potentials (fIJPs) in proximal and distal colonic muscles from control and dextran sodium sulfate (DSS)-colitis mice. (A, B) Atropine (1 $\mu$ M) and MRS2500 (1 $\mu \mathrm{M})$ blocked excitatory junction potentials and decreased fIJPs but exhibited no effect on slow inhibitory junctional potentials (sIJPs) in colonic muscles of control and DSS-colitis mice. (C, D) Summary of the data showing the average amplitude of sIJPs with the presence of atropine and MRS2500 in the proximal and distal colonic muscles of control and DSS-colitis mice (in the proximal colon, $\mathrm{n}=6 /$ group, ${ }^{*} P<0.05$; in the distal colon, $\mathrm{n}=6$ /group, $\left.{ }^{*} P<0.05\right)$.

few studies have been performed to demonstrate the myogenic and neurogenic mechanisms of colonic transit disorder. Thus, this study focused on the function of ICC and ANO1 channels, as an important component of the SIP syncytium, in the regulation of colonic motility in DSS-colitis. We know that the mutual coordination of the SIP syncytium (including ICC, PDGFR $\alpha^{+}$cells, and SMCs) leads to normal GI motility results. ${ }^{30}$ Myogenic contractions result from the actions of interstitial cells (ICC and PDGFR $\alpha^{+}$cells) and their ionic channels that are electrically coupled to SMCs that generate regular contraction and relaxation in colonic transit from the oral to the anal end. ${ }^{26,31,32}$ Additionally, NO inhibitory neurotransmitters that are released by enteric motor neurons could activate ANO1 channels in ICC to decrease the excitability of SMCs. ${ }^{33}$ Thus, any changes of conductance or neurotransmitters in SIP cells can influence excitability and eventually result in colonic transit dysmotility. However, a previous study reported that nitrergic and purinergic neurotransmitters were the critical mediators of spon- taneous neuromuscular activity, rather than acetylcholine, which demonstrated that the inhibitory nitrergic signalling pathway plays a dominant role in mediating the colonic motility of CMMC. ${ }^{34}$ The nitrergic inhibitory response is regulated by ANO1 channels in the ICC of smooth muscle. ${ }^{17,19}$ Thus, this outcome provides a good direction to explore the functional changes of ICC and its channels in neuromuscular transit dysmotility.

In the present study, the expressions of ICC and ANO1 were decreased in colitis colons (Fig. 2). However, the alterations in ICC and ANO1 affect the transit disorder of colitis. Thus, colonic transit was first compared between normal and DSS-colitis mice in CMMC experiments and is the main form of colon transmission. We determined that the colonic transit of DSS-colitis was disordered with the contractile amplitudes and frequencies obviously inconsistent and disordered compared with the regular transit in control mice (Fig. 3A and 3B). Next, artificial pellet propulsion experiment was performed through isolation of the entire colon or- 
gan to compare the CMMC between the control and colitis mice. The observation that colonic transit was significantly delayed in DSS-colitis mice (Fig. 3C and 3D) may be not only due to the downregulation of ICC but also probably related to a hypersensitive and poorly compliant inflamed colon, which leads to frequent and urgent defecation. Although an increased frequency of bowel movements were observed during severe colitis, it may not cause increased total CMMCs. This result is supported by Rao et al. ${ }^{35-37}$ These results showed that downregulated ICC and ANO1 channels indeed led to colonic transit dysmotility in colitis mice.

ANO1 channels are highly expressed in ICC and are activated by $\mathrm{NO}$ from the enteric neuromuscular bundle that generates outward $\mathrm{Cl}^{-}$currents. ${ }^{5}$ Thus, ANO1 channels are the key factor to the inhibitory NO function for ICC in the GI tract. ${ }^{17,23}$ Accordingly, the antagonist of ANO1 channel and $\mathrm{NO}$ were applied to explore the contributions of CMMC dystransit in DSS-colitis. In this study, the usage of the ANO1 channel antagonist NPPB or NO antagonist L-NAME significantly reduced or enhanced the CMMCs and spontaneous contractions of colonic smooth muscles. Importantly, the colonic smooth muscles were all more insensitive to NPPB and L-NAME in DSS-colitis than in control mice (Fig. 4 and 5). These findings revealed that the under-expressed ANO1 channels lead to the downregulation of the excitatory function of ICC that are electrically coupled to SMCs in the generation of CMMC, which induced an irregular contraction wave of colitis. In addition, electrophysiological studies have displayed that ICC mediate smooth muscle excitability via acting on the MP by gap junction connectivity to SMCs. ${ }^{38}$ In this article, intracellular electronic recordings demonstrated that in control mice, NPPB elicited prominent hyperpolarization in colonic SMCs, which indicated that blocking ANO1 channels decreased smooth muscle excitability (Fig. 6). Moreover, in DSS-colitis mice, NPPB evoked smaller amplitudes of hyperpolarization in colitic SMCs, which indicated the downregulated function of ANO1 channels. The results suggested that the excitability of colitis is relatively decreased when the expression of ANO1, which induces excitation, is downregulated, which lead to the occurrence of colonic transit disorder in clinical patients with UC.

It has been widely accepted that ICC are pivotal targets of nitric neurotransmitter in GI smooth muscles, and they mediate the sIJP induced by inhibitory NO in colonic muscles. ${ }^{17}$ Moreover, sIJP is a small-amplitude, brief hyperpolarization of the ICC and electrically coupled SMC, which is a consequence of the tonic release of inhibitory neurotransmitters $\mathrm{NO}{ }^{39}$ In the present study, to explore the functional changes of ICC in DSS-colitis mice, we detected the dif- ferences of sIJP between the control and DSS-colitis mice. Intracellular electronic recordings showed that in the absence and presence of both MRS2500 and atropine blocking the fIJP, the amplitude of sIJP of colonic smooth muscles was consistently smaller in the DSS-colitis mice than that in control mice, elucidating that colonic smooth muscles suffered decreased nitric inhibition from the EFS (3, 6, $9 \mathrm{~Hz}$ ) of enteric neurons (Fig. 7 and 8). These results certify that colonic transit dysmotility in DSS colitis may reflect the functional downregulation of ICC and ANO1 channels by inhibiting the excitability and contractions of colonic smooth muscle.

In summary, colonic transit is mediated by inhibitory and excitatory neurons, and the target of the neurotransmitter, whether it is excitatory or inhibitory, mainly focuses on the SIP syncytium. In DSS-colitis mice, the protein and mRNA expression levels of ICC and ANO1 channels were downregulated in colitis smooth muscle layers. Moreover, the colonic smooth muscles were more insensitive to the antagonists of SK3 channel and NO in DSS-colitis mice. These results demonstrate that the functional downregulation of the ICC/ANO1 channel signalling pathway disturbs the balance between ICC and PDGFR $\alpha^{+}$cell functions from the SIP syncytium, induces dysregulation of colonic smooth muscle contraction, and eventually result in transit disorder in colitis mice. These results provide a further explanation for illustrating the mechanism of colonic transit disorder in UC patients with severe dysmotility. Meanwhile, our study has expanded the present knowledge regarding the potential role of ICC and its channel ANO1 in IBD, and it may lead the way in developing a possible therapeutic strategy for IBD treatment.

Acknowledgements: Poster presentation at the Chinese Association for Physiological Sciences, Nan Chang, Jiangxi Province, October 2018.

Financial support: This work was approved by the National Natural Science Foundation of China (Grant No. 31671192 and 31571180 ) and Foundation of Xin Hua Hospital (Grant No. JZPI201708).

\section{Conflicts of interest: None.}

Author contributions: Chen Lu: design and conduct of experiments; summary, analysis, and explanation of data; drafting of the article; and revision of the paper seriously for important intellectual content; Hongli Lu, Xu Huang, Shaohua Liu, Jingyu Zang, and Yujia Li: collection, analysis, and interpretation of data; Jie Chen: conception and design of experiments, and analysis and interpreta- 
tion of data; and Wenxie $\mathrm{Xu}$ : hypothesis and design of experiments, analysis and illustration of data, and revision of the paper critically for important intellectual content. All authors supported the final version of the manuscript.

\section{References}

1. German AJ, Hall EJ, Day MJ. Chronic intestinal inflammation and intestinal disease in dogs. J Vet Intern Med 2003;17:8-20.

2. Villanacci V, Bassotti G, Nascimbeni R, et al. Enteric nervous system abnormalities in inflammatory bowel diseases. Neurogastroenterol Motil 2008;20:1009-1016.

3. Quigley EM. What we have learned about colonic motility: normal and disturbed. Curr Opin Gastroenterol 2010;26:53-60.

4. De Giorgio R, Barbara G, Furness JB, Tonini M. Novel therapeutic targets for enteric nervous system disorders. Trends Pharmacol Sci 2007;28:473-481.

5. Blair PJ, Rhee PL, Sanders KM, Ward SM. The significance of interstitial cells in neurogastroenterology. J Neurogastroenterol Motil 2014;20:294-317.

6. Durnin L, Lees A, Manzoor S, Sasse KC, Sanders KM, MutafovaYambolieva VN. Loss of nitric oxide-mediated inhibition of purine neurotransmitter release in the colon in the absence of interstitial cells of Cajal. Am J Physiol Gastrointest Liver Physiol 2017;313:G419-G433.

7. Bharucha AE. Lower gastrointestinal functions. Neurogastroenterol Motil 2008;20(suppl 1):103-113.

8. Bernardini N, Segnani C, Ippolito C, et al. Immunohistochemical analysis of myenteric ganglia and interstitial cells of Cajal in ulcerative colitis. J Cell Mol Med 2011;16:318-327.

9. Sanders KM, Ward SM, Koh SD. Interstitial cells: regulators of smooth muscle function. Physiol Rev 2014;94:859-907.

10. Faussone Pellegrini MS, Cortesini C, Romagnoli P. [Ultrastructure of the tunica muscularis of the cardial portion of the human esophagus and stomach, with special reference to the so-called Cajal's interstitial cells.] Arch Ital Anat Embriol 1977;82:157-177. [Italian]

11. Gomez-Pinilla PJ, Gibbons SJ, Bardsley MR, et al. Ano1 is a selective marker of interstitial cells of Cajal in the human and mouse gastrointestinal tract. Am J Physiol Gastrointest Liver Physiol 2009;296:G1370G1381.

12. Hwang SJ, Blair PJ, Britton FC, et al. Expression of anoctamin 1/ TMEM16A by interstitial cells of Cajal is fundamental for slow wave activity in gastrointestinal muscles. J Physiol 2009;587(Pt 20):4887-4904.

13. Zhu $\mathrm{MH}$, Kim TW, Ro S, et al. $\mathrm{A} \mathrm{Ca}^{2+}$-activated $\mathrm{Cl}^{-}$conductance in interstitial cells of Cajal linked to slow wave currents and pacemaker activity. J Physiol 2009;587(Pt 20):4905-4918.

14. Al-Shboul OA. The importance of interstitial cells of Cajal in the gastrointestinal tract. Saudi J Gastroenterol 2013;19:3-15.

15. Groneberg D, Voussen B, Friebe A. Integrative control of gastrointestinal motility by nitric oxide. Curr Med Chem 2016;23:2715-2735.

16. Beckett EA, Sanders KM, Ward SM. Inhibitory responses mediated by vagal nerve stimulation are diminished in stomachs of mice with reduced intramuscular interstitial cells of Cajal. Sci Rep 2017;7:44759.

17. Lies B, Beck K, Keppler J, Saur D, Groneberg D, Friebe A. Nitrergic signalling via interstitial cells of Cajal regulates motor activity in murine colon. J Physiol 2015;593:4589-4601.

18. Kaji N, Horiguchi K, lino $\mathrm{S}$, et al. Nitric oxide-induced oxidative stress impairs pacemaker function of murine interstitial cells of Cajal during inflammation. Pharmacol Res 2016;111:838-848.

19. Groneberg D, Lies B, König P, et al. Cell-specific deletion of nitric oxide-sensitive guanylyl cyclase reveals a dual pathway for nitrergic neuromuscular transmission in the murine fundus. Gastroenterology 2013;145:188-196.

20. McNamee EN, Wermers JD, Masterson JC, et al. A novel model of $\mathrm{T}_{\mathrm{H}}$ 2-polarized chronic ileitis: the SAMP1 mouse. Inflamm Bowel Dis 2010;16:743-752.

21. Neudecker V, Haneklaus M, Jensen O, et al. Myeloid-derived miR-223 regulates intestinal inflammation via repression of the NLRP3 inflammasome. J Exp Med 2017;214:1737-1752.

22. Abbaspour Babaei M, Kamalidehghan B, Saleem M, Huri HZ, Ahmadipour F. Receptor tyrosine kinase (c-Kit) inhibitors: a potential therapeutic target in cancer cells. Drug Des Devel Ther 2016;10:2443-2459.

23. Singh RD, Gibbons SJ, Saravanaperumal SA, et al. Ano1, a $\mathrm{Ca}^{2+}$ activated $\mathrm{Cl}^{-}$- channel, coordinates contractility in mouse intestine by $\mathrm{Ca}^{2+}$ transient coordination between interstitial cells of Cajal. J Physiol 2014;592:4051-4068.

24. Terauchi A, Kobayashi D, Mashimo H. Distinct roles of nitric oxide synthases and interstitial cells of Cajal in rectoanal relaxation. Am J Physiol Gastrointest Liver Physiol 2005;289:G291-G299.

25. Roman LJ, Martásek P, Masters BS. Intrinsic and extrinsic modulation of nitric oxide synthase activity. Chem Rev 2002;102:1179-1190.

26. Kurahashi M, Zheng H, Dwyer L, Ward SM, Koh SD, Sanders KM. A functional role for the 'fibroblast-like cells' in gastrointestinal smooth muscles. J Physiol 2011;589(Pt 3):697-710.

27. Song NN, Lu HL, Lu C, et al. Diabetes-induced colonic slow transit mediated by the up-regulation of PDGFR $\alpha^{+}$cells/SK 3 in streptozotocin-induced diabetic mice. Neurogastroenterol Motil 2018;30:e13326.

28. Érces D, Varga G, Fazekas B, et al. N-methyl-d-aspartate receptor antagonist therapy suppresses colon motility and inflammatory activation six days after the onset of experimental colitis in rats. Eur J Pharmacol 2012;69:225-234.

29. Chandrasekharan B, Jeppsson S, Pienkowski S, et al. Tumor necrosis factor -neuropeptide $\mathrm{Y}$ cross talk regulates inflammation, epithelial barrier functions, and colonic motility. Inflamm Bowel Dis 2013;19:2535-2546.

30. Sanders KM, Koh SD, Ro S, Ward SM. Regulation of gastrointestinal motility - insights from smooth muscle biology. Nat Rev Gastroenterol Hepatol 2012;9:633-645.

31. Komuro T. Structure and organization of interstitial cells of Cajal in the gastrointestinal tract. J Physiol 2006;576(Pt 3):653-658.

32. Lu C, Huang X, Lu HL, et al. Different distributions of interstitial cells of Cajal and platelet-derived growth factor receptor- $\alpha$ positive cells in colonic smooth muscle cell/interstitial cell of Cajal/platelet-derived growth factor receptor- $\alpha$ positive cell syncytium in mice. World $\mathrm{J}$ Gastroenterol 2018;24:4989-5004. 
33. Lee H, Koh BH, Peri LE, Sanders KM, Koh SD. Purinergic inhibitory regulation of murine detrusor muscles mediated by PDGFRalpha ${ }^{+}$ interstitial cells. J Physiol 2014;592:1283-1293.

34. Gil V, Gallego D, Grasa L, Martín MT, Jiménez M. Purinergic and nitrergic neuromuscular transmission mediates spontaneous neuronal activity in the rat colon. Am J Physiol Gastrointest Liver Physiol 2010;299:G158-G169.

35. Rao SS, Read NW, Brown C, Bruce C, Holdsworth CD. Studies on the mechanism of bowel disturbance in ulcerative colitis. Gastroenterology 1987;93:934-940.

36. Drewes AM, Frøkjaer JB, Larsen E, Reddy H, Arendt-Nielsen L, Gregersen $\mathrm{H}$. Pain and mechanical properties of the rectum in patients with active ulcerative colitis. Inflamm Bowel Dis 2006;12:294-303.

37. Haase AM, Gregersen T, Christensen LA, et al. Regional gastrointestinal transit times in severe ulcerative colitis. Neurogastroenterol Motil 2016;28:217-224.

38. Horiguchi K, Sanders KM, Ward SM. Enteric motor neurons form synaptic-like junctions with interstitial cells of Cajal in the canine gastric antrum. Cell Tissue Res 2003;311:299-313.

39. Opazo A, Lecea B, Gil V, Jiménez M, Clavé P, Gallego D. Specific and complementary roles for nitric oxide and ATP in the inhibitory motor pathways to rat internal anal sphincter. Neurogastroenterol Motil 2010;23:e11-e25. 